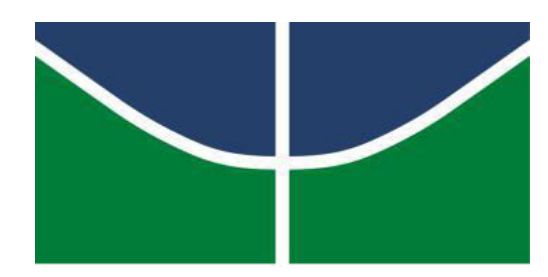

UNIVERSIDADE DE BRASÍLIA

FACULDADE DE CIÊNCIAS DA SAÚDE

PÓS-GRADUAÇÃO EM CIÊNCIAS FARMACÊUTICAS

DAIANE MEDEIROS DE OLIVEIRA

PRODUÇÃO E PURIFICAÇÃO DO PEPTÍDEO HEMOPRESSINA VISANDO POTENCIAL FARMACOLÓGICO

BRASÍLIA-DF 


\section{PRODUÇÃO E PURIFICAÇÃO DO PEPTÍDEO HEMOPRESSINA VISANDO POTENCIAL FARMACOLÓGICO}

Dissertação apresentada ao Programa de Pós-Graduação em Ciências Farmacêuticas, da Faculdade de Ciências da Saúde, Universidade de Brasília, como requisito para a obtenção do título de Mestre em Ciências Farmacêuticas.

Área de concentração: Ciências Farmacêuticas.

Orientadora: Profa. Dra. Maria Fátima Grossi de Sá.

BRASÍLIA-DF 
Autorizo a reprodução e divulgação total ou parcial deste trabalho, por qualquer meio convencional ou eletrônico, para fins de ensino, estudo ou pesquisa, desde que citada a fonte.

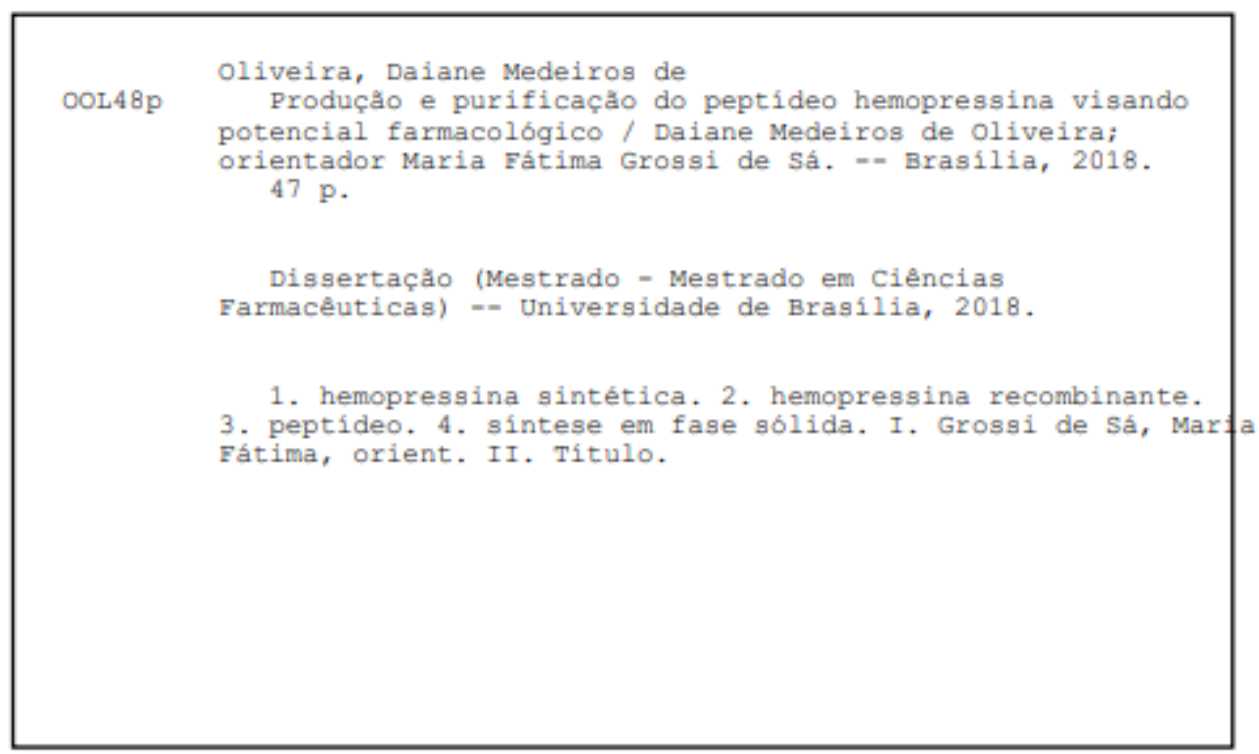




\section{PRODUÇÃO E PURIFICAÇÃO DO PEPTÍDEO HEMOPRESSINA VISANDO POTENCIAL FARMACOLÓGICO}

Dissertação apresentada ao Programa de Pós-Graduação em Ciências Farmacêuticas, Faculdade de Ciências da Saúde, Universidade de Brasília, como requisito para a obtenção do título de Mestre em Ciências Farmacêuticas.

Aprovada em 30 de Janeiro de 2018.

BANCA EXAMINADORA

Profa. Dra. Maria Fátima Grossi de Sá

(Presidente)

Universidade de Brasília

Profa. Dra. Pérola de Oliveira Magalhães Dias Batista

(Membro titular interno)

Universidade de Brasília

Prof. Dr. Érico Augusto Rosas de Vasconcelos

(Membro titular externo)

Centro Universitário UNIEURO

Profa. Dra. Maria de Fátima Borin

(Membro Suplente)

Universidade de Brasília 


\section{LISTA DE FIGURAS}

Figura 1- Mapa do vetor de expressão recombinante pGEX-4T-1 18

Figura 2- SDS-PAGE e Western blotting do extrato proteico da expressão da hemopressina em Escherichia coli. 26

Figura 3- SDS-PAGE do extrato proteico da expressão da hemopressina fusionada a GST, em Escherichia coli.

Figura 4- Quantificação por densitometria do extrato proteico da expressão da hemopressina fusionada a GST, em Escherichia coli

Figura 5- SDS-PAGE da hemopressina purificada por cromatografia de afinidade em resina Glutathione Sepharose 4 Fast Flow (GE) 31

Figura 6- Espectros de massa dos produtos brutos de síntese das hemopressinas 33

Figura 7- Espectro de fragmentação (MS/MS) do produto principal de síntese de hemopressina humano 34

Figura 8- Espectro de fragmentação (MS/MS) do produto principal de síntese de hemopressina sequência de murino 35

Figura 9- Purificação das hemopressinas sintéticas 36

Figura 10- Espectros de massa das hemopressinas purificadas 37 
LISTA DE TABELAS

Tabela 1- Peptídeos bioativos derivados da hemoglobina

Tabela 2- Parâmetros de expressão da hemopressina

Tabela 3- Parâmetros gerais e de maior expressão da hemopressina 28 


\section{LISTA DE ABREVIATURAS}

BSA (Bovine Serum Albumin)

Albumina do Soro Bovino

CB1 Canabinoide 1

CB2 Canabinoide 2

$\mathrm{Da}$ Daltons

DIPEA $\mathrm{N}$-etil-N-propan-2-ilpropan-2-amina ou $\mathrm{N}, \mathrm{N}$-diisopropiletilamina DMSO Dimetilsufóxido

GST Glutationa S-Transferase HBTU

........Hexafluorofosfato de [benzotriazol-1-iloxi(dimetilamino)metilideno]-dimetilazânio Hp Hemopressina HPLC .Cromatografia Líquida de Alta Eficiência ICV intracerebroventricular ip intraperitoneal IPTG Isopropyl $\beta$-D-1-thiogalactopyranoside

LB Luria-Bertani PLGA poli(ácido lático-co-glicólico) $\mathrm{SNC}$ Sistema Nervoso Central 
Dedico este trabalho a Deus, a $\mathcal{N}$ ossa Senhora Aparecida, a minha filfinha Camila, aos meus pais Olando e Sônia, e aos meus irmãos Tiago, Eduardo e Paulo Henrique. 


\section{AGRADECIMENTOS}

A Deus e a Nossa Senhora Aparecida, pela força espiritual para superar todos os desafios ao longo dessa jornada.

A minha filhinha Camila Medeiros. Por me ensinar o verdadeiro sentido da vida, e a ser cada vez mais forte. Você é meu tudo. Te amo demais!

Aos meus pais Olando Medeiros e Sônia Ferreira. Apesar da distância, estão sempre presentes, torcendo pelas minhas conquistas. Agradeço por todo apoio e orações.

Aos meus irmãos Tiago, Eduardo e Paulo Henrique. Obrigada por todo incentivo e por acreditarem em mim.

A minha orientadora Dra. Maria Fátima Grossi de Sá. Sou muito agradecida pela oportunidade que me deu, por ter me recebido em seu laboratório. Também agradeço pelas palavras de incentivo para a vida profissional e pessoal.

Ao meu professor e amigo Dr. Érico Vasconcelos. Quem me apresentou o mundo científico e sempre está comigo nessa caminhada. É para mim uma grande referência como profissional e pessoa.

Ao pesquisador Dr. Marcelo Porto Bemquerer. Por quem tenho enorme respeito e admiração pela sua competência. Sempre muito paciente e disposto a ajudar. Agradeço imensamente pela colaboração neste trabalho, o qual possibilitou a realização da síntese química das hemopressinas. 
Ao Dr. Leonardo Pepino, analista do Laboratório Interação Molecular PlantaPraga. Pelo apoio prestado ao longo desse trabalho.

A professora Dra. Maria de Fátima Borin. Na época, como coordenadora do Programa de Pós Graduação em Ciências Farmacêuticas, me deu abertura para conhecer sobre o mesmo, e assim, fazer a seleção. Agradeço também por participar da banca da minha defesa de mestrado.

A professora Dra. Pérola Magalhães. Por ter me aceitado como aluna em Estágio em Docência. E agora compor a banca da minha defesa de mestrado.

Aos meus grandes amigos e colegas de laboratório Ana Elizabeth, Elínea e Joel. A Angelina, Vanessa e demais colegas do LIMPP, da Embrapa Recursos Genéticos e Biotecnologia. Pelo convívio, ajuda cotidiana e sugestões para a realização do mestrado.

A Dra. Patrícia Pelegrini, pelos ensinamentos no início do mestrado. Pela contribuição neste trabalho.

A minha amiga Dra. Ariane Lacerda, pelos ensinamentos nos meus primeiros passos na vida científica.

A Dra. Magda Beneventi, pela participação na minha fase introdutória científica. 


\section{RESUMO}

OLIVEIRA, Daiane Medeiros de. Produção e purificação do peptídeo hemopressina visando potencial farmacológico. Dissertação (Mestrado em Ciências Farmacêuticas) Faculdade de Ciências da Saúde, Universidade de Brasília, Brasília 2018.

A hemopressina é um nonapeptídeo derivado da cadeia $\alpha-1$ de hemoglobina de mamíferos que é conhecido pelos seus efeitos hipotensivo, analgésico e supressor do apetite. Este peptídeo age como um agonista inverso ou antagonista do receptor canabinoide CB1. Disfunções no sistema endocanabinoide, estão associadas com algumas patologias e morbidade, tais como obesidade, dor neuropática, depressão, inflamação, mal de Alzheimer e doença de Parkinson. O presente estudo teve por objetivo produzir a hemopressina nas formas sintética e recombinante, e purificar as moléculas produzidas, visando futura avaliação das suas propriedades biológicas. Para a obtenção do peptídeo recombinante, a sequência nucleotídica que codifica a hemopressina foi inserida no vetor de expressão pGEX-4T-1® (GE Healthcare) fusionada ao tag-GST e expressa em Escherichia coli BL21-CodonPlus. Várias condições de expressão foram testadas para determinar os melhores parâmetros de expressão. A síntese em fase sólida da hemopressina de formas humana e murina foi realizada utilizando a estratégia Fmoc/tButil. As sequências de resíduos de aminoácidos de ambas as formas da hemopressina foram confirmadas por espectrometria de massa MALDI no modo LIFT $^{\mathrm{TM}}$ em um equipamento de Autoflex Speed (BrukerDaltonics, Bilerica, EUA). A purificação do peptídeo sintético foi realizada por cromatografia de fase reversa (Shimadzu LC-20AT) numa coluna C18 semi-preparativa (Jupiter $5 \mu \mathrm{m}$ $300 \AA$ A). Análises por espectrometria de massa das hemopressinas humana e murina mostraram peptídeos sintéticos com massa molecular de 1.053,6 Da e 1.087,6 Da, respectivamente. A massa molecular da hemopressina recombinante de murino fusionada à GST foi de aproximadamente $31 \mathrm{kDa}$, obtida por meio de análise de SDSPAGE e confirmada por Western Blotting. O rendimento da expressão foi avaliado por densitometria, que constatou a produção de $147,8 \mathrm{mg} / \mathrm{L}$ da proteína recombinante.

Palavras chaves: hemopressina sintética, hemopressina recombinante, peptídeo, síntese em fase sólida. 


\begin{abstract}
OLIVEIRA, Daiane Medeiros de. Produção e purificação do peptídeo hemopressina visando potencial farmacológico. Dissertação (Mestrado em Ciências Farmacêuticas) Faculdade de Ciências da Saúde, Universidade de Brasília, Brasília 2018.

Hemopressin is a nonapeptide derived from the $\alpha-1$ chain of mammalian hemoglobin known for its hypotensive, analgesic and appetite suppressive effects. This peptide acts as a CB1 cannabinoid receptor inverse agonist or antagonist. Dysfunctions in the endocannabinoid system are associated with some pathologies and morbidity, such as obesity, neuropathic pain, depression, inflammation, Alzheimer and Parkinson diseases. This study was focused on the production and purification of synthetic and recombinant hemopressin, aiming future evaluation of their biological properties. To obtain the recombinant peptide, the nucleotide sequence encoding hemopressin was inserted into the expression vector pGEX-4T-1 (GE Healthcare) fused to the tag-GST and expressed in Escherichia coli BL21-CodonPlus. Several expression conditions were tested to determine the best expression parameters. Solid-phase synthesis of human and murine hemopressin was performed using the Fmoc/t-butyl strategy. The amino acid sequences of both forms of hemopressin was confirmed by MALDI mass spectrometry in the LIFT $^{\mathrm{TM}}$ mode at an Autoflex speed equipment (BrukerDaltonics, Bilerica, USA). Purification of the synthetic peptide was performed by reversed-phase chromatography (Shimadzu LC-20AT) on a C18 semi-preparative column (Jupiter $5 \mu \mathrm{m} 300 \AA$ A). Mass spectrometric analysis of human and murine hemopressins showed synthetic peptides with a molecular mass of 1,053.6 Da and 1,087.6 Da, respectively. The molecular mass of murine recombinant hemopressin fused to GST was approximately $31 \mathrm{kDa}$, a value that was obtained by SDS-PAGE analysis and confirmed by Western Blotting. The expression yield was evaluated by densitometry, which showed an equivalent expression yield of $147,8 \mathrm{mg} / \mathrm{L}$ of the recombinant protein.
\end{abstract}

Key words: synthetic hemopressin, recombinant hemopressin, peptide, solid-phase peptide synthesis. 


\section{SUMÁRIO}

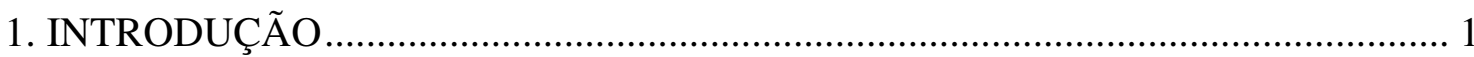

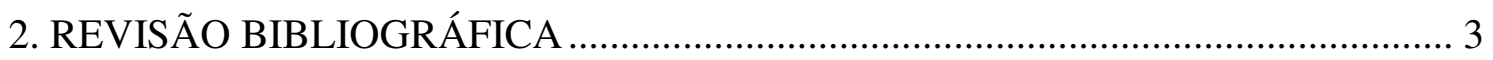

2.1 Síntese de peptídeos ........................................................................................ 3

2.1.1 Expressão heteróloga de peptídeos bioativos em Escherichia coli................. 4

2.1.2 Produção de peptídeos bioativos por síntese em fase sólida ............................ 6

2.2 Peptídeo hemopressina como candidato na aplicação terapêutica.......................... 9

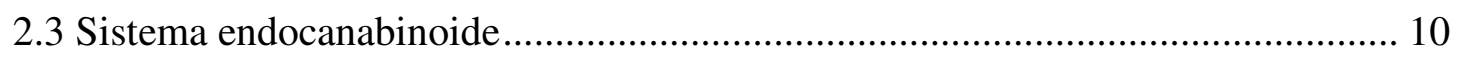

2.4 Hemopressina e suas propriedades farmacológicas ............................................ 10

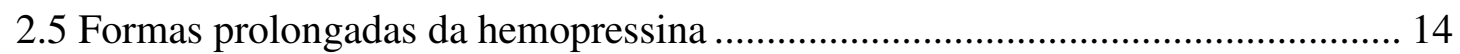

2.6 Outros peptídeos derivados da hemoglobina .................................................. 14

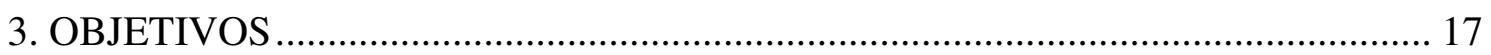

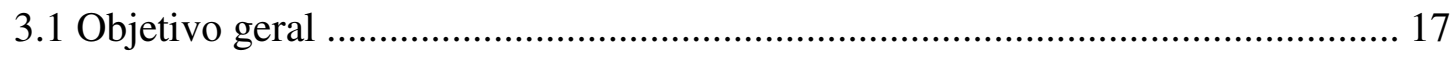

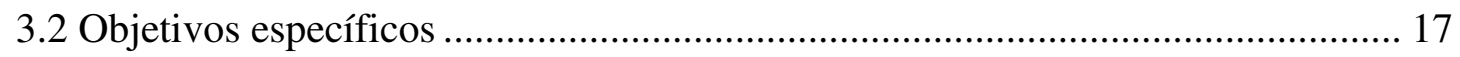

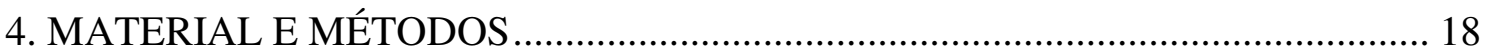

4.1 Transformação de Escherichia coli BL21 CodonPlus por choque térmico........... 18

4.2 Produção da hemopressina recombinante e padronização das condições de

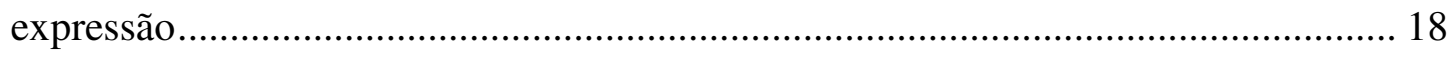

4.3 Quantificação do nível de expressão da hemopressina........................................ 20

4.4 Confirmação da expressão da hemopressina fusionada a GST por Western Blot 21

4.5 Purificação da hemopressina recombinante ....................................................... 22

4.6 Síntese dos peptídeos em fase sólida e sequenciamento.................................... 22

4.7 Purificação das hemopressinas sintéticas por Cromatografia Líquida de Alto

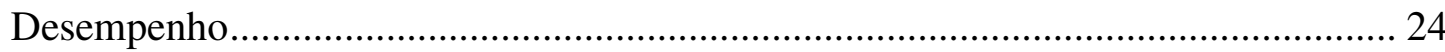




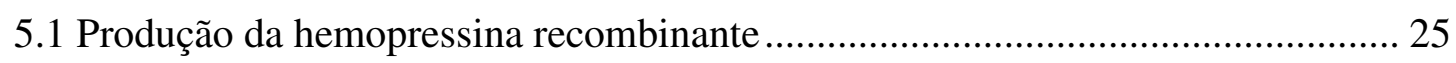

5.2 Quantificação do nível de expressão de hemopressina recombinante 26

5.3 Purificação da hemopressina fusionada à GST por cromatografia de afinidade .. 30 5.4 Obtenção por síntese em fase sólida e sequenciamento das hemopressinas sintéticas. 32

5.5 Purificação das hemopressinas sintéticas 36

6. CONCLUSÃO. 39

7. PERSPECTIVAS FUTURAS 40

8. REFERÊNCIAS 41 


\section{INTRODUÇÃO}

A hemopressina é um nonapeptídeo derivado da cadeia $\alpha-1$ da hemoglobina de mamíferos. Tendo sido identificada a partir de extrato de cérebro de ratos, a hemopressina é descrita pelos seus efeitos hipotensor, analgésico, inibidor de apetite, promotor da melhora da formação e da retenção da memória prolongada, potencial atuação no tratamento de doenças desmielinizantes e atenuação da fibrose hepática. Este peptídeo atua como um antagonista ou agonista inverso do receptor canabinoide CB1 (RIOLI et al., 2003; DALE et al., 2005; DODD et al., 2010; XAPELLI et al., 2014; EL SWEFY et al., 2015; ZHANG et al., 2016).

Os receptores CB1 juntamente com os receptores CB2 e seus ligantes endógenos compõem o sistema endocanabinoide, o qual tem sido amplamente estudado pelas suas funções reguladoras em saúde e doença. A modulação desse sistema tornou-se uma possibilidade de aplicação para diversas doenças e condições patológicas, tais como distúrbios de humor e ansiedade, doença de Parkinson, dor neuropática, esclerose múltipla, obesidade, dentre outras (PACHER et al., 2006). Os receptores CB1 e CB2 pertencem à superfamília dos receptores de membrana acoplados à proteína $\mathrm{G}$, sendo esses mais abundantes em células do sistema imunológico. Já os receptores CB1 são mais expressos no sistema nervoso central (FRANCISCHETTI \& ABREU, 2006; GODOY-MATOS et al., 2006).

Nos últimos tempos tem havido um grande interesse pela modulação do receptor canabinoide CB1. A identificação de antagonistas deste receptor tem sido um dos principais avanços nas pesquisas de canabinoides, tornando esses ligantes como novas possibilidades em aplicações terapêuticas. O rimonabanto [5-(4-clorofenil)-1-(2,4diclorofenil)-4-metil- $N$-piperidin-1-ilpirazola-3-carboxamida] foi o primeiro antagonista do receptor canabinoide identificado pela Sanofi, em 1994 (JAGEROVIC et al., 2008).

Os peptídeos e as proteínas terapêuticos apresentam especificidade e atividade elevadas em baixas concentrações, tornando-os por esse motivo, indispensáveis no tratamento de diversas doenças (WANG et al., 1999). O mercado de drogas peptídicas está em ascensão, apresentando o dobro do crescimento em relação às outras drogas, promovendo crescente impacto clínico e econômico (D’HONDT et al., 2014). Estas moléculas podem ser obtidas a partir de diferentes fontes, dentre estas por síntese química em fase sólida e síntese pela tecnologia do DNA recombinante (JULIANO, 1990; VLIEGHE et al., 2010; VAN DORPE et al., 2011). 
Desde 2004, o governo brasileiro vem estimulando o desenvolvimento de produtos e processos inovadores por instituições e empresas brasileiras, especialmente na produção de biofármacos (BRASIL, 2004; PIMENTA, 2008; ÍNTEGRA BRASIL, 2011). A hemopressina apresenta-se como uma potencial biomolécula para o tratamento de doenças e condições patológicas associadas ao sistema endocanabinoide (XAPELLI et al., 2014; ZHANG et al., 2016). Muitas dessas doenças e condições dispõem de medicamentos que constam na Relação Nacional de Medicamentos Essenciais (RENAME) (BRASIL, 2017). Devido à importância das condições patológicas associadas ao sistema endocanabinoide, bem como dos fármacos utilizados nos tratamentos convencionais, este estudo visou a produzir em sistema heterólogo e por síntese química, o peptídeo hemopressina, para posteriormente avaliar seu potencial farmacológico. 


\section{REVISÃO BIBLIOGRÁFICA}

\subsection{Síntese de peptídeos}

Os peptídeos e as proteínas são biomoléculas compostas por resíduos de aminoácidos unidos por ligações peptídicas. As proteínas constituem as macromoléculas mais abundantes nas células vivas, as quais desempenham funções vitais nos processos biológicos. Desempenham funções variadas, tais como catálise, transporte e armazenamento de moléculas, também atuam na imunidade, na transmissão de impulsos nervosos, no controle do crescimento e diferenciação celular (MELO et al., 2012).

Assim como as proteínas, os peptídeos apresentam ampla diversidade química e funcional. Contudo, são moléculas pequenas, apresentando de dois a dezenas de resíduos de aminoácidos. Os peptídeos ativos foram descobertos e tiveram suas estruturas químicas determinadas a partir da década de 1950. Desde então, com o conhecimento sobre essas moléculas, foram sendo desenvolvidas técnicas para o seu isolamento, análise, purificação, identificação e quantificação, as quais foram sendo aprimoradas. Com isto, surgiu a necessidade de sintetizar essas moléculas e análogos destas, em diferentes escalas, permitindo a realização de estudos sobre o papel biológico dos peptídeos naturais. Em paralelo, também foram sendo desenvolvidas técnicas para a manipulação, síntese e clonagem de genes (MACHADO et al., 2004).

A maioria dos peptídeos bioativos é originada de proteínas precursoras grandes, por clivagem por meio de peptidases, seguidos de armazenamento em vesículas secretoras, de onde são liberados por estimulação celular. Os neurotransmissores de peptídeos, neuropeptídeos clássicos e peptídeos hormonais, são exemplos desses peptídeos bioativos (GOMES et al., 2010).

Os peptídeos e as proteínas terapêuticos apresentam especificidade e eficácia elevadas em baixas concentrações, tornando-os por esse motivo, indispensáveis no tratamento de diversas doenças (WANG et al., 1999). Em comparação com as proteínas, os peptídeos, por serem pequenos, apresentam maior capacidade para penetrar mais profundamente o tecido alvo. Além disso, os peptídeos com atividade terapêutica apresentam a vantagem de serem menos imunogênicos e mais econômicos para serem produzidos segundo os parâmetros de qualidade exigidos, relacionados às proteínas e 
anticorpos (VLIEGHE et al., 2010). Os peptídeos terapêuticos também apresentam várias vantagens, em comparação às pequenas moléculas orgânicas que compõe os medicamentos tradicionais, uma vez que, muitas vezes são constituídos da menor parte funcional de uma proteína, promovendo maior eficácia, seletividade e especificidade. Os peptídeos também apresentam menos interações medicamentosas, pelo fato dos produtos de degradação peptídica serem constituídos por aminoácidos. Além disso, tendo em vista que apresentam curto tempo de meia vida, poucos peptídeos se acumulam nos tecidos, reduzindo os riscos de complicações causados por seus metabólitos (VLIEGHE et al., 2010; FOSGERAU e HOFFMANN, 2015).

Nos últimos anos, diversas estratégias têm sido aplicadas visando o melhoramento na produção e para a redução do metabolismo de peptídeos, juntamente com as vias de administração, levando ao aumento da comercialização dessas drogas. Os peptídeos terapêuticos podem ser obtidos a partir de diferentes fontes, tais como: extração de fontes naturais; síntese em animais ou plantas transgênicas; síntese em solução ou clássica; síntese em fase sólida; síntese enzimática; síntese pela tecnologia do DNA recombinante (JULIANO, 1990; VLIEGHE et al., 2010; VAN DORPE et al., 2011).

\subsubsection{Expressão heteróloga de peptídeos bioativos em Escherichia coli}

Com o advento da produção de proteínas recombinantes, a aplicação de proteínas terapêuticas e de diagnóstico como biofarmacêutica modificou consideravelmente. Por meio da tecnologia do DNA recombinante passou a ser possível a obtenção de grande quantidade dessas moléculas (MALIK, 2016). Além disso, tornouse uma alternativa para a produção de moléculas grandes, mais de vinte e cinco resíduos de aminoácidos, pelo custo-efetividade, produção em escala de gramas e quilogramas e sustentabilidade. O estudo de peptídeos visando à aplicação terapêutica passou a ser objeto de interesse da indústria farmacêutica por apresentarem baixa toxicidade, alta especificidade e alta atividade biológica. Contudo, ainda existem muitos desafios quanto à sua produção, especialmente relacionado à síntese, escala e purificação (RODRÍGUEZ et al., 2014). 
A produção de proteínas recombinantes em sistemas microbianos revolucionou a bioquímica. Os sistemas hospedeiros incluem bactérias, leveduras, fungos filamentosos e algas unicelulares, sendo necessária a avaliação do sistema mais adequado de acordo com as características da proteína de interesse (ROSANO \& CECCARELLI, 2014). A Escherichia coli foi o primeiro hospedeiro utilizado para fabricação de um biofármaco, que resultou na aprovação regulamentar da insulina humana em 1982 para o tratamento da diabetes mellitus (BAESHEN et al., 2015). E. coli continua sendo amplamente empregada na pesquisa básica e em aplicações farmacêuticas, como o método mais popular e econômico (CHEN et al., 2012; LEBENDIKER \& DANIELI, 2014), sendo o sistema de escolha da indústria de biotecnologia para produção em grande escala principalmente de proteínas não glicosiladas (BAESHEN et al., 2015). Além disso, E. coli é o sistema de expressão bacteriano mais utilizado na produção de proteínas terapêuticas recombinantes aprovadas, representando cerca de $30 \%$ da produção dessas moléculas. A preferência por este sistema na indústria biotecnológica dá-se principalmente pelo rápido crescimento celular, fácil manipulação genética e rendimento elevado de síntese proteica (HUANG et al., 2012; BAESHEN et al., 2015). Associadas à essas vantagens, o conhecimento sobre as vias genéticas e bioquímicas de E. coli é bem aprofundado (MALIK, 2016). Além disso, esse sistema dispõe de diversas ferramentas biológicas aplicáveis em escala industrial, tais como cepas de produção, vetores de expressão, enovelamento de proteínas e tecnologias de fermentação. Com todos os avanços, atualmente este sistema tem possibilitado também a expressão de proteínas complexas tais como glicoproteínas humanizadas e anticorpos aglicosilados de comprimento total (HUANG et al., 2012).

Contudo, mesmo com progressos significativos na transcrição, tradução e translocação, a produção de proteínas solúveis e bioativas ainda é um desafio (MALIK, 2016). Um problema importante é a agregação das proteínas, a qual pode ser resultante de fatores intrínsecos a essas moléculas, como a formação de folhas beta que dá origem aos fragmentos do tipo amiloide (RINAS et al., 2017) ou por fatores relacionados à expressão e às condições de purificação. No processo de expressão, a incompatibilidade da maquinaria bacteriana para efetuar o enovelamento de proteínas de origem eucariótica, pode contribuir para a agregação. Na etapa de purificação, condições físicoquímicas deste processo influenciam no dobramento da proteína. Desta forma, diversas estratégias são aplicadas com o objetivo de reduzir a agregação, aumentar a solubilidade 
e a atividade das proteínas recombinantes, tais como o uso de cepas bacterianas especializadas, vetor de expressão, o uso de promotores adequados a essa condição, tags para melhorar a solubilidade, avaliação das melhores condições de crescimento, concentração do indutor e duração da indução. Além disso, condições durante o processamento de purificação podem ser relevantes, como condições do tampão para a purificação (LEBENDIKER \& DANIELI, 2014; PAPANEOPHYTOU \& KONTOPIDIS, 2014). Também a redução da temperatura de crescimento está associada ao aumento da solubilidade de proteínas recombinantes, redução da agregação de proteínas, e minimização da formação de corpos de inclusão. Por meio desta abordagem, foi observada maior solubilidade de várias proteínas terapêuticas tais como interferon- $\alpha-2$ e hormônio de crescimento humano (BAESHEN et al., 2015).

\subsubsection{Produção de peptídeos bioativos por síntese em fase sólida}

Os peptídeos compõem um grupo que têm-se destacado notadamente entre os produtos farmacêuticos, posicionados entre pequenas moléculas orgânicas clássicas e biomoléculas maiores, como proteínas. O mercado de drogas peptídicas está em ascensão, apresentando o dobro do crescimento em relação às outras drogas, promovendo crescente impacto clínico e econômico. Atualmente, a maioria dos peptídeos é produzida por síntese química em fase sólida (D’HONDT et al., 2014).

A síntese de peptídeos de fase sólida (SPPS) foi desenvolvida em 1963 por Merrifield, a qual representou um novo conceito de síntese de peptídeos. A SPPS apresenta como característica, a criação de uma cadeia peptídica, a partir da adição consecutiva de aminoácidos, fixada pelo aminoácido C-terminal a um polímero sólido por ligação covalente (MERRIFIELD, 1963). Durante o processamento da SPPS, podem ocorrer reações secundárias, acarretando em diversos tipos de impurezas peptídicas, tais como: estruturas de dicetopiperazina, resíduos de aspartimida, racemização de cisteína, oxidação e redução de resíduos de aminoácidos, produtos diastereoisoméricos, dímeros, inserções ou deleções de aminoácidos, produtos de reatividade da cadeia lateral e modificações de resíduos de aminoácidos durante a clivagem. Desta forma, o produto bruto da SPPS, pode apresentar muitos subprodutos, mas essas impurezas podem ser removidas pela purificação cromatográfica (VERBEKE et al., 2015). 
A síntese química de peptídeos para fins terapêuticos tornou-se economicamente viável e com possibilidade de produção de peptídeos de diferentes tamanhos, desde cinco até cerca de cinquenta resíduos (VERBEKE et al., 2015). Nos últimos trinta anos houve um grande aumento no interesse em relação aos medicamentos peptídicos por parte da comunidade científica. Este interesse também se expandiu ao mercado, estimando um valor de U\$ 15 bilhões por ano, sendo que mais de $85 \%$ das vendas são derivadas de peptídeos sintéticos. Além disso, o valor de mercado para os medicamentos peptídicos vem apresentado crescimento muito maior do que para outros produtos farmacêuticos, o que é significativo quanto se considera que o mercado global de produtos farmacêuticos apresentou taxa de crescimento anual de $10 \%$ entre 2006 e 2010. Em 2012, diversos novos fármacos peptídicos, com aplicações variadas, foram aprovados, entre eles incluem-se os seguintes: Linzess $®$, Surfaxin $®$, Kyprolis $₫$, Gattex ${ }^{\circledR}$, Bydureon ${ }^{\circledR}$, Signifor ${ }^{\circledR}$, indicados para o tratamento de constipação crônica e síndrome do intestino irritável em adultos, síndrome de distúrbio respiratório infantil (IRDS), mieloma múltiplo, síndrome do intestino curto (SBS) em adultos, diabetes tipo 2 e doença de Cushing, respectivamente (D'HONDT et al., 2014).

A síntese química orgânica fundamenta-se no uso de reagentes e catalisadores para a formação de ligações, e no uso de grupos protetores adequados para prevenção da formação de ligações indesejadas e de reações secundárias, sendo essencial a escolha correta dos grupos de proteção para o sucesso deste processo (ISIDRO-LLOBET et al., 2009). No processo de síntese de peptídeo em fase sólida é empregada uma resina inerte e insolúvel sobre a qual são adicionados os derivados de aminoácidos como uma cadeia crescente. Desta forma, o primeiro derivado de aminoácido é anexado na resina, seguido de acoplamentos individuais de aminoácidos, envolvendo etapas de desproteção, acoplamento e lavagens, até inserir toda a sequência de aminoácidos, e ao final realizase a clivagem da resina (VAN DORPE et al., 2011).

A proteção da cadeia lateral (grupo R) dos aminoácidos com grupamentos orgânicos reativos como a amina, a carboxila, a sulfidrila e a guanidina é uma das questões mais importantes e obrigatórias no processo de síntese química de peptídeos, para prevenir a polimerização do resíduo de aminoácido incorporado. Tendo em vista que, a maioria das sínteses de peptídeos, tanto em solução quanto em fase sólida, é realizada no sentido C-terminal para $\mathrm{N}$-terminal, os grupos $\mathrm{R}$-aminoprotetores (grupos de proteção temporários) são removidos várias vezes durante o processamento da síntese. Sendo assim, esta remoção deve ocorrer em condições suaves para não afetar os 
grupos de proteção permanentes das cadeias laterais, os quais, geralmente são removidos no final da síntese peptídica (ISIDRO-LLOBET et al., 2009).

O grupo protetor do radical amino deve promover solubilidade ao derivado de aminoácido correspondente nos solventes mais comuns. Além disso, deve prevenir ou minimizar a epimerização durante as etapas de acoplamento, sua remoção precisa ser rápida, eficiente e livre de reações secundárias, deve ter rendimento próximo de $100 \%$, eliminando subprodutos. Os grupos R-amino-protetores mais comuns para a síntese de peptídeos por fase sólida são o 9-fluorenilmetoxicarbonil (Fmoc) e os grupos tertbutiloxicarbonila (Boc), utilizados nas estratégias Fmoc/tert-butil (tBu) e Boc/benzil (Bn), respectivamente (ISIDRO-LLOBET et al., 2009). O grupo 9fluorenilmetoxicarbonil (Fmoc) apresenta estabilidade em relação aos ácidos e hidrogenação catalítica, e é facilmente clivado em condições ligeiramente básicas, não hidrolíticas (CARPINO \& HAN, 1972). Além disso, o Fmoc é um grupamento químico que permite a ligação de aminoácidos à estrutura da resina e também promove proteção do aminoácido durante o acoplamento na cadeia polimérica de peptídeos (MACHADO et al., 2004).

A etapa de acoplamento consiste na formação de uma ligação amida e na adição subsequente de um resíduo de aminoácido ao peptídeo, resultante do ataque nucleofílico do grupo amino de um aminoácido ao grupo carboxílico do outro aminoácido, resultando na ligação peptídica. Para que ocorra este processo, o grupo de proteção Fmoc é removido antes da adição de cada derivado de aminoácido por meio da indução por base. Ao final do processo de síntese, deve-se realizar a reação de clivagem do peptídeo e da resina, procedimento no qual se efetua a remoção simultânea da resina e dos grupos protetores das cadeias laterais por acidólise (MACHADO et al., 2004; D’HONDT et al., 2014). Por fim, para que o peptídeo possa ser utilizado em testes biológicos e estruturais, uso clínico ou para o consumo alimentar, o processo de purificação é indispensável para a obtenção da molécula com alto grau de pureza, igual ou superior a 95\%. Para tanto existem diferentes técnicas cromatográficas para a purificação dos produtos brutos de síntese química. Dentre elas as mais empregadas são cromatografia líquida de fase reversa, troca iônica, exclusão e de afinidade (MACHADO et al., 2004). 


\subsection{Peptídeo hemopressina como candidato na aplicação terapêutica}

A biotecnologia desempenha importante papel no desenvolvimento de diversos produtos, destacando-se as aplicações na área farmacêutica. Desde 2004, o governo brasileiro investe em empresas que possuem a tecnologia da produção de biomedicamentos, apostando no caráter estratégico da biotecnologia e na possível diminuição de custos na importação e produção de medicamentos no país (PIMENTA, 2008). Desta forma, a Lei de Inovação Tecnológica $n^{0} 10.973$, de 2 de dezembro de 2004, estimula o desenvolvimento de produtos e processos inovadores por empresas brasileiras (ÍNTEGRA BRASIL, 2011). É conhecida a existência de diversas moléculas, já bem descritas na literatura, que apresentam características aplicáveis para utilização como biofármacos. Dentre estas, encontra-se a hemopressina, um peptídeo derivado da hemoglobina, o qual por meio de ligação aos receptores canabinoides CB1 tem demonstrado potencial nos efeitos hipotensor (RIOLI et al., 2003), antinociceptivo (DALE et al., 2005; HEIMANN et al., 2007) e diminuição na ingestão de alimentos (DODD et al., 2010). Também tem demonstrado atividades diferenciadas, tais como no aumento da diferenciação e maturação de oligodendrócitos em células estaminais (XAPELLI et al., 2014), e atenuação da fibrose hepática induzida por colestase em ratos (EL SWEFY et al., 2015).

A hemopressina apresenta-se promissora com possível aplicação no tratamento de doenças e disfunções associadas ao sistema endocanabinoide, além de sua provável atividade na obesidade (DODD et al., 2010; ZHOU et al., 2012; XAPELLI et al., 2014; EL SWEFY et al., 2015; ZHANG et al., 2016). Este potencial dá-se pelo fato da hemopressina atuar como agonista inverso ou antagonista dos receptores canabinoides CB1, os quais fazem parte do sistema endocanabinoide. Muitas patologias associadas a esse sistema representam grande relevância clínica (PACHER et al., 2006), algumas delas com medicamentos para tratamento pertencentes à relação de medicamentos essenciais, tais como depressão, dor neuropática, mal de Alzheimer e doença de Parkinson (PACHER et al., 2006; BRASIL, 2017).

As características estruturais da hemopressina, tratando-se de uma molécula pequena e de fácil manipulação, juntamente com suas evidências terapêuticas relatadas (BLAIS et al., 2005; DODD et al, 2010; ZHOU et al., 2012), bem como o incentivo da produção de biofármacos no Brasil (PIMENTA, 2008), justificam uma análise mais 
profunda deste peptídeo como possível candidato a uma biomolécula com atividade no tratamento de doenças relacionadas às disfunções do sistema endocanabinoide.

\subsection{Sistema endocanabinoide}

Os receptores CB1 e CB2 fazem parte do sistema endocanabinoide, o qual está associado a diversos processos biológicos, como apetite, memória, atividade imunológica, cognição, sensação de dor, respostas comportamentais. Muitas fisiopatologias de importância clínica são decorrentes de alterações desse sistema, como obesidade, dor neuropática, mal de Alzheimer, doença de Parkinson, depressão e inflamação, tornando-os alvos no desenvolvimento de novos fármacos (IVERSEN \& CHAPMAN, 2002; BOYD, 2006; PACHER et al., 2006; HEIMANN et al., 2007; DI MARZO \& PETROSINO, 2007; BOMAR \& GALANDE, 2013). O sistema endocanabinoide é altamente associado à obesidade, ao consumo exagerado de alimentos e ao acúmulo de gordura (BOYD, 2006).

Os receptores canabinoides pertencem a uma classe de receptores acoplados à proteína G (BEGG et al., 2005), e são os principais alvos dos canabinoides endógenos, denominados de endocanabinoides, os quais são compostos por receptores e ligantes endógenos (MACKIE, 2006; DI MARZO, 2008). Tais receptores são divididos em CB1 e CB2, sendo estes expressos principalmente em células imunes (GOMES et al., 2009), enquanto que os receptores $\mathrm{CB} 1$ são expressos principalmente no sistema nervoso central (FRANCISCHETTI \& ABREU, 2006). Entre os ligantes dos receptores canabinoides CB1 destacam-se canabinoides endógenos (anandamida), agonistas sintéticos (rimonabanto), fitoanabinoides como $\Delta^{9-}$ tetrahidrocannabinol (derivados de Cannabis sativa) (BOMAR \& GALANDE, 2013).

Pelo fato do sistema endocanabinoide ser atuante em diversas categorias de doenças, isso o torna um alvo terapêutico para o tratamento de patologias, tais como distúrbios de humor e ansiedade, dor neuropática, hipertensão, síndromes metabólicas, inflamação, esclerose múltipla e obesidade (PACHER et al., 2006).

\subsection{Hemopressina e suas propriedades farmacológicas}

A hemopressina é um peptídeo composto por nove resíduos de aminoácidos (PVNFKFLSH), derivado da cadeia $\alpha 1$ (95-103) da hemoglobina de mamíferos, tais 
como humanos, ratos, bovinos e suínos. Entre essas espécies, a sequência do peptídeo difere apenas na posição 100 da cadeia $\alpha-1$ da hemoglobina (FERRO, 2010; REDDY et al., 2012). Tal molécula foi identificada a partir de extrato de cérebro de ratos, como substrato peptídico para as metalopeptidases cataliticamente inativas das Endopeptidase EP 24.15 (EP 24.15), Neurolisina EP 24.16 (EP 24.16) e para a Enzima Conversora de Angiotensina (ECA), as quais participam do metabolismo de neuropeptídeos em vertebrados. Ambas as peptidases compartilham a maioria de seus substratos naturais, os quais são hidrolisados na mesma ligação peptídica (RIOLI et al., 2003). Ainda nesse estudo, a hemopressina mostrou ser metabolizada in vivo $\mathrm{e}$ in vitro pelas endopeptidases, indicando atividade vasoativa in vivo. Administrada via intravenosa, a hemopressina demonstrou efeito hipotensor dose-dependente em ratos anestesiados com pentobarbital, 5-etil-5-pentan-2-il-1,3-diazinano-2,4,6-triona (RIOLI et al., 2003).

A hemopressina também demonstrou ação antinociceptiva periférica na hiperalgesia experimental em ratos, induzida por carragenina e bradicinina. Por meio deste estudo, Dale et al. (2005), constataram que a hemopressina desempenha atividade não-opioide, pois não inibiu a resposta do naloxona (antagonista de receptores opioides), de modo diferente das hemorfinas, derivadas da $\beta$-globina. Por meio de truncamentos na região carboxi-terminal da hemopressina, foram estudados dois fragmentos da molécula (PVNFKF e PVNFKFL), com o mesmo potencial da sua forma intacta. Entretanto, fragmentos mais curtos (PVNFK e PVNF) foram inativos (DALE et al., 2005). O efeito analgésico dose-dependente da hemopressina também foi observado por Zhou et al. (2012), a partir da hiperalgesia induzida por endoquinina A/B (EKA/B) e endoquinina $\mathrm{C} / \mathrm{D}(\mathrm{EKC} / \mathrm{D})$ via supra-espinhal em camundongos, confirmando a atividade antagonista do peptídeo, administrada por via intracerebroventricular.

O efeito antinociceptivo da hemopressina, também foi constato por Heimann et al. (2007), quando o peptídeo foi administrado pelas vias intratecal, intraplantar e oral. Neste mesmo estudo, constatou-se a seletividade da hemopressina pelos receptores canabinoides CB1, por meio da utilização de anticorpos sensíveis ao estado de conformação para diversos receptores acoplados a proteína $\mathrm{G}$, dentre eles, os receptores opioides e canabinoides, demonstrando atividade antagonista ou agonista inversa aos receptores CB1, uma vez que foi capaz de bloquear a atividade constitutiva destes receptores como o antagonista rimonabanto. Além da ativação dos receptores CB1, a hemopressina (PVNFKFLSH) e o seu fragmento C-terminal truncado hemopressina 17 (PVNFKFL), mostraram leve efeito modulador no sistema opioide (SZLAVICZ et al., 
2015). Também no estudo de ligação e funcionalização do fragmento peptídico hemopressina marcada radioativamente (1-7) (PVNFKFL) mostrou ligação independente de CB1 em cérebro de rato tipo selvagem e a má ativação das proteínas G. Isto demonstra ser a hemopressina um suposto regulador indireto ou ligante alostérico do sistema endocanabinoide e não um ligante endógeno do receptor CB1 (DVORACSKO et al., 2016).

A atividade hipotensora da molécula foi avaliada por Blais et al. (2005). Administrada por via intravenosa ou intra-arterial, a hemopressina promoveu alteração da pressão arterial em coelho, rato e camundongo. Ainda nesse estudo, os autores observaram a degradação do peptídeo pela ECA, por ensaio in vitro. Em 2006, Lippton et al. (2006), a partir de um estudo para avaliar os efeitos da hemopressina administrada via intravenosa sobre a pressão arterial sistêmica, saída cardíaca e resistência vascular sistêmica em ratos anestesiados, constataram a ocorrência de dilatação da câmara vascular sistêmica através da liberação endógena de óxido nítrico, indicando possível atuação vasodilatadora.

Num estudo da atividade da hemopressina no comportamento de alimentação, demonstrou-se que a administração central (intracerebroventricular) ou sistêmica (intraperitoneal) do peptídeo em ratos e camundongos, também em camundongos obesos $o b / o b$, promoveu uma diminuição dose-dependente na ingestão diária de alimentos sem causar efeitos colaterais óbvios (DODD et al.; 2010). O estudo de Dodd et al., reforçou os receptores canabinoides CB1 como alvo da hemopressina, como já havia indicado Heimann et al.; (2007), uma vez que não houve diminuição na ingestão de alimentos por camundongos que não possuíam tais receptores (DODD et al., 2010).

A atividade da hemopressina foi observada por Xapelli et al. (2014), no aumento da diferenciação e maturação de oligodendrócitos em células estaminais, progenitoras neurais de ratos neonatos, sugerindo possível aplicação da molécula para o tratamento de doenças desmielinizantes (XAPELLI et al., 2014). Também em outro estudo, a hemopressina promoveu atenuação da fibrose hepática induzida por colestase em ratos, parecendo potencializar o efeito hepatoprotetor da curcumina. Tal efeito pareceu ser mediado pelos receptores canabinoides (EL SWEFY et al., 2015).

$\mathrm{Na}$ análise do efeito comportamental da hemopressina em ratos submetidos a testes de labirinto elevado, constatou-se o efeito ansiogênico do peptídeo administrado pelas vias intraperitoneal, oral e intracerebroventricular, sugerindo que tal efeito ocorra pela ativação da hemopressina dos receptores TRPV1. Em contrapartida, acredita-se que 
o efeito ansiogênico nas outras duas vias aconteça em decorrência da passagem de fragmento (s) da hemopressina pela barreira hematoencefálica (FOGAÇA et al., 2015).

A hemopressina e as suas formas $\mathrm{N}$-terminal estendidas VD-hemopressina e RVD-hemopressina, demonstraram aplicação possível também no tratamento de patologias relacionadas ao déficit de memória, como na doença de Alzheimer. Desta forma, tais moléculas foram investigadas na memória em camundongos abordando novas tarefas de reconhecimento de objetos (NOR) e reconhecimento de localização de objetos (OLR). Quando administrada antes do treinamento via intracerebroventricular em ratos normais, a hemopressina promoveu a melhora da formação e da retenção da memória prolongada nas tarefas. Entretanto, VD e RVD-hemopressina exibiram efeitos prejudiciais à memória. Contudo, as moléculas reverteram o comprometimento da memória em camundongos em modelos de doença de Alzheimer induzida por proteína amiloide- $\beta$ (A $\beta 1-42)$ administrada 14 dias antes do treinamento. Nesses animais, a hemopressina (ICV) ou AM251 (2 mg/Kg, i.p.) suprimiu os efeitos de RVDhemopressina e VD-hemopressina. Em contrapartida, quando administrada sozinha, a Hp não promoveu atividade nos camundongos tratados com A $\beta 1-42$ (ZHANG et al., 2016).

$\mathrm{Na}$ análise do efeito comportamental emocional em ratos, foram administrados via intraperitoneal hemopressina $(0,05 \mathrm{mg} / \mathrm{kg})$ e RVD-hemopressina $(\alpha)(0,05 \mathrm{mg} / \mathrm{kg})$. A RVD-hemopressina induziu ao comportamento ansiolítico e antidepressivo, promovendo o aumento das monoaminas (dopamina, norepinefrina e 5hidroxitriptamina) e diminuição da expressão gênica de enzimas (MAO-B e COMT) envolvidas no seu catabolismo. Em contrapartida, a hemopressina promoveu efeito oposto, uma vez que estimulou ao comportamento ansiogênico e depressivo, além de ter causado a queda nos níveis de estado estacionário de monoaminas e elevação das enzimas, no córtex pré-frontal (LEONE et al., 2017).

Em análise por espectrometria de massa, Gelman et al. (2010), identificaram que diversos peptídeos derivados da hemoglobina são encontrados apenas no cérebro, enquanto que, todos os peptídeos derivados da hemoglobina presentes no coração também foram encontrados no sangue. Este resultado indica que a produção de vários peptídeos derivados da hemoglobina, incluindo a hemopressina, ocorre a partir de hemoglobina cerebral e não de eritrócitos (GELMAN et al., 2010). 


\subsection{Formas prolongadas da hemopressina}

Por espectrometria de massa, Gomes et al. (2009) identificaram formas prolongadas na região N-terminal da hemopressina, apresentando três resíduos de aminoácidos adicionais (RVD-Hpa) ou dois resíduos adicionais (VD-Hpa). Além do peptídeo derivado da cadeia $\beta$ da hemoglobina, VD-Hp $\beta$ (VDPENFRLLCNM), assim denominado por apresentar semelhanças à sequência da hemopressina. Diferentemente da hemopressina, esses peptídeos demonstraram atividade agonista de receptores CB1. Assim sendo, a diferença de apenas dois ou três resíduos de aminoácidos pareceu ser determinante na atividade agonista ou antagonista no receptor CB1 (GOMES et al., 2009).

Também foram observadas diferenças nas atividades de RVD-hemopressina (agonista dos receptores CB1), em relação à hemopressina. Administrada por via intracerebroventricular em ratos, a RVD-hemopressina inibiu a ativação da saída de fluxo adrenomedular central, inibindo o aumento das catecolaminas (noradrenalina e adrenalina), induzidas por bombesina. Entretanto, esta resposta não foi observada com a hemopressina (agonista inverso dos receptores CB1) (TANAKA et al., 2014).

Em análise in vitro, a VD-hemopressina $(\alpha)$ de rato estimulou o crescimento de neurites em células Neuro2A via receptor CB1. Também através desse receptor, o peptídeo promoveu efeito antinociceptivo central em camundongos. Quando administrada via supra-espinhal, induziu a hipotermia e a sua administração ICV causou hipoatividade. Ademais, a VD-hemopressina $(\alpha)$ induziu o desenvolvimento de tolerância antinociceptiva (ZHENG et al., 2017).

\subsection{Outros peptídeos derivados da hemoglobina}

A hemoglobina é uma proteína citosólica, a qual apresenta uma estrutura tetramérica composta por duas cadeias $\alpha$ e duas cadeias $\beta$ (RICHTER et al., 2009; GELMAN \& FRICKER, 2010). As cadeias são precursoras de diversos peptídeos bioativos, dentre eles as neoquiotorfinas, as hemorfinas e as hemopressinas (NYBERG et al., 1997; FUKUI et al., 1983; RIOLI et al., 2003). Apesar da hemoglobina ser um dos principais componentes das hemácias, também pode ser encontrada nos neurônios e na glia. Sendo assim, vários peptídeos derivados da hemoglobina (Tabela 1) localizam- 
se em cérebros de camundongos, e muitos apresentam atividades bioativas como as hemopressinas (GELMAN et al., 2010).

As hemorfinas foram isoladas e identificadas a partir de sangue bovino tratado enzimaticamente. São pequenos peptídeos derivados da região $\mathrm{N}$-terminal da cadeia $\beta$ da hemoglobina, e apresentam afinidade aos receptores opioides (NYBERG et al., 1997; ZHAO et al., 1997). As hemorfinas promovem redução da pressão arterial, por inibir a atividade da enzima conversora de angiotensina (LANTZ et al., 1991) e apresentam efeito antinociceptivo (DAVIS et al., 1989).

Isolada de cérebro bovino por cromatografia de filtração em gel e cromatografia de permuta catiônica, a neoquiotorfina (Thr-Ser-Lys-Tyr-Arg), corresponde à região Cterminal da cadeia $\alpha$ da hemoglobina. A sua forma sintética demonstrou efeito analgésico em camundongos e interação com receptores de angiotensina (FUKUI et al., 1983; KISO et al., 1983). 
Tabela 1. Peptídeos bioativos derivados da hemoglobina.

\begin{tabular}{|c|c|c|c|c|}
\hline & Nome peptídeo & $\begin{array}{l}\text { Sequência } \\
\text { peptídeo }\end{array}$ & Alvos biológicos & Funções biológicas \\
\hline $\begin{array}{l}\mathrm{Hpa}_{138-} \\
142\end{array}$ & Neoquiotorfina & TSKYR & Desconhecido & $\begin{array}{c}\text { Analgésico não opioide; termorregulação; proteção contra } \\
\text { convulsões; modulação da influência vagal no ritmo cardíaco; } \\
\text { antibacteriano; indução à proliferação de adipócitos e células } \\
\text { cancerígenas }\end{array}$ \\
\hline $\begin{array}{l}\mathrm{Hpa}_{141-} \\
\quad 142\end{array}$ & Quiotorfina & YR & Desconhecido & Analgésico não opioide \\
\hline $\begin{array}{c}\mathrm{Hpa}_{96-} \\
104\end{array}$ & Hemopressina & PVNFKFLSH & Receptores canabinoides CB1 & $\begin{array}{l}\text { Indução da hipotensão; antinociceptivo não opioide; anti- } \\
\text { hiperalgésico; reduz a ingestão de alimentos }\end{array}$ \\
\hline $\begin{array}{l}\mathrm{Hp \alpha}_{93-} \\
104\end{array}$ & RVD-Hpa & RVDPVNFKFLSH & Receptores canabinoides CB1 & Desconhecido \\
\hline $\begin{array}{l}\mathrm{Hpa}_{93-} \\
\quad 104\end{array}$ & VD-Hpa & VDPVNFKFLSH & Receptores canabinoides CB1 & Desconhecido \\
\hline$H p \beta_{37-40}$ & Hemorfina-4 & YPWT & Receptores de opioides & Antinocicepção \\
\hline$H p \beta_{37-43}$ & Hemorfina-7 & YPWTQRF & Receptores de opioides & Antinocicepção; anti-inflamatório \\
\hline $\mathrm{Hp} \boldsymbol{\beta}_{35-43}$ & VV-hemorfina-7 & VVYPWTQRF & $\begin{array}{l}\text { Receptores de opioides e } \\
\text { bombesina } 3\end{array}$ & Antinocicepção \\
\hline$H p \beta_{34-43}$ & $\begin{array}{l}\text { LVV-hemorfina- } \\
\qquad 7\end{array}$ & LVVYPWTQRF & $\begin{array}{l}\text { Receptores de opioides, } \\
\text { angiotensina IV e bombesina } 3 \\
\text { enzima conversora de } \\
\text { angiotensina }\end{array}$ & $\begin{array}{l}\text { Antinocicepção; regulação da pressão arterial; aprendizagem } \\
\text { e } \\
\text { memória; potenciação da transmissão colinérgica }\end{array}$ \\
\hline $\begin{array}{c}\mathrm{Hp} \beta_{99-} \\
110\end{array}$ & VD-Hp $\beta$ & $\begin{array}{l}\text { VDPENFRLLCN } \\
\mathrm{M}\end{array}$ & $\begin{array}{l}\text { Receptores canabinoides CB1 e } \\
\text { CB2 }\end{array}$ & Desconhecido \\
\hline
\end{tabular}

Fonte: GOMES et al., 2010. Adaptado. 


\section{OBJETIVOS}

\subsection{Objetivo geral}

Produzir as hemopressinas humana e murina nas formas recombinante e sintética.

\subsection{Objetivos específicos}

- Expressar a hemopressina em sistema bacteriano;

- Realizar a síntese em fase sólida da hemopressina;

- Purificar a hemopressina nas formas sintética e recombinante utilizando métodos de cromatografia. 


\section{MATERIAL E MÉTODOS}

\subsection{Transformação de Escherichia coli BL21 CodonPlus por choque térmico}

Para a obtenção da molécula recombinante, a sequência nucleotídica codificadora do peptídeo hemopressina (sequência da forma murina PVNFKFLSH, 1.087,6 Da), foi sintetizada pela empresa GenScript (Estados Unidos) e incorporada ao vetor de expressão pGEX4t-1 (GE), estando fusionada a extremidade 5' da tag GST (Figura 1) para expressão a hemopressina recombinante em células de E. coli e posterior purificação. $\mathrm{O}$ vetor utilizado apresenta o promotor tac, que é induzido pelo análogo de lactose 2-propil- $\beta$-D-1-tiogalactopiranosídeo (IPTG), o qual apresenta capacidade de conduzir a altos níveis de expressão.

Células competentes de E. coli BL21 CodonPlus no volume de $50 \mu \mathrm{L}$ foram transformadas com 100 ng da construção, por choque térmico, utilizando-se ampicilina a $100 \mu \mathrm{g} / \mathrm{mL}$ e cloranfenicol a $25 \mu \mathrm{g} / \mathrm{mL}$ como agentes seletivos. Posteriormente, um clone foi selecionado e deste foi feito um stab $(700 \mu \mathrm{L}$ de glicerol $80 \%+300 \mu \mathrm{L}$ de meio LB contendo a colônia 5) e armazenado a $-20{ }^{\circ} \mathrm{C}$.

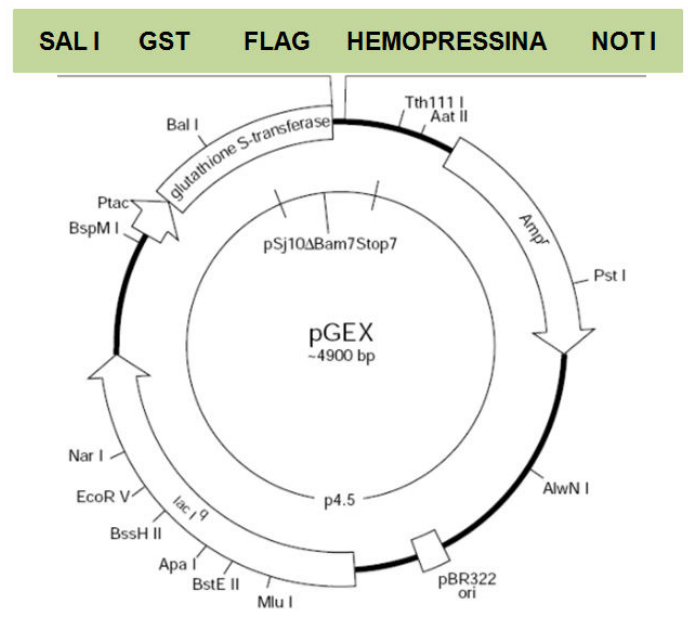

Figura 1. Mapa do vetor de expressão recombinante pGEX-4T-1. A sequência nucleotídica codificadora da hemopressina de murino foi inserida entre os sítios de clivagem de Sal I e Not I, juntamente com a sequência "tag" de GST. Entre a "tag" GST e o gene da hemopressina foi inserido um sítio de clivagem para enteroquinase (FLAG).

\subsection{Produção da hemopressina recombinante e padronização das condições de} expressão

Para o preparo do pré-inóculo, foram utilizados $5 \mu \mathrm{L}$ desse $s t a b, 5 \mathrm{~mL}$ de meio Luria-Bertani (LB) (1\% de triptona, $0,5 \%$ de extrato de levedura, $0,5 \%$ de cloreto de 
sódio, $\mathrm{pH} 7,0$ ), contendo ampicilina $100 \mu \mathrm{g} / \mathrm{mL}$ e cloranfenicol a $25 \mu \mathrm{g} / \mathrm{mL}$, a $37{ }^{\circ} \mathrm{C}$, 200 rotações por minuto $(\mathrm{rpm})$ durante 16 horas. Após este período, foram realizadas expressões com $50 \mathrm{~mL}$ de meio $\mathrm{LB}$, contendo $100 \mu \mathrm{g} / \mathrm{mL}$ de ampicilina e $25 \mu \mathrm{g} / \mathrm{mL}$ cloranfenicol, e utilizando volume de 1:10 do pré-inóculo, que foram então incubados a $37^{\circ} \mathrm{C}, 200 \mathrm{rpm}$ até que a absorbância (OD600) atingisse valores entre 0,6 a 0,8.

Para padronização das melhores condições de rendimento de expressão da hemopressina, foram testados diferentes parâmetros (Tabela 2) como meio de cultivo LB e 4YT (0,5\% de cloreto de sódio, 3,2\% de triptona, $2 \%$ extrato de levedura, $\mathrm{pH} 7,0)$, temperatura e concentrações variadas do indutor IPTG, além do sistema não induzido (sem adição de IPTG). Os pré-inóculos foram incubados a $37^{\circ} \mathrm{C}$ e as expressões foram realizadas sob diferentes condições.

Tabela 2. Parâmetros de expressão da hemopressina

\begin{tabular}{|c|c|c|c|c|c|}
\hline \multirow{2}{*}{$\begin{array}{c}\text { Meio de } \\
\text { Cultivo }\end{array}$} & $\begin{array}{c}\text { Temperatura } \\
\left({ }^{\circ} \mathbf{C}\right)\end{array}$ & \multicolumn{4}{|c|}{ Concentração do Indutor (mM) } \\
\hline \multirow{4}{*}{ LB } & 15 & 0 & 0,25 & 0,5 & 1 \\
\cline { 2 - 6 } & 20 & 0 & 0,25 & 0,5 & 1 \\
\cline { 2 - 6 } 4 YT & 25 & 0 & 0,25 & 0,5 & 1 \\
\cline { 2 - 6 } & 30 & 0 & 0,25 & 0,5 & 1 \\
\cline { 2 - 6 } & 37 & 0 & 0,25 & 0,5 & 1 \\
\hline
\end{tabular}

Os produtos de expressão foram analisados em gel de SDS-PAGE 15\% (sodium dodecyl sulfate polyacrylamide gel electrophoresis) (SAMBROOK \& RUSSELL, 2006), a $15 \mathrm{~mA}$ (miliampere) no gel concentrador e a $20 \mathrm{~mA}$ no gel separador, e o marcador de peso molecular BenchMark Protein Ladder (Invitrogen). Os géis foram corados com Coomassie blue (metanol 40\%, ácido acético 10\%, água estéril 50\%, 2 gramas de brilliant blue G Sigma -B5133) e, em seguida descorados com solução descorante (40\% metanol, 10\% ácido acético, 50\% água estéril).

Após a otimização das condições de expressão, foi realizada nova expressão e precipitação das células para separação das proteínas solúveis e insolúveis. Dessa forma, após o término da expressão, as células (todo volume de expressão) foram 
precipitadas por centrifugação, a $4000 \mathrm{rpm}, 5$ minutos, $25{ }^{\circ} \mathrm{C}$. O sobrenadante foi descartado e o sedimento foi solubilizado com PBS (140 mM de $\mathrm{NaCl}, 2,7 \mathrm{mM} \mathrm{KCl}, 10$ $\mathrm{mM} \mathrm{Na} 2 \mathrm{HPO}_{4}, 1,8 \mathrm{mM} \mathrm{KH}{ }_{2} \mathrm{PO}_{4}, \mathrm{pH}$ 7,3) na concentração $1 \mathrm{X}$, volume de 1:20 referente ao volume do meio de cultura utilizado na expressão. A esta solução foram adicionados PMSF (fluoreto de fenilmetanossulfonila) $10 \mathrm{mM}$ e benzamidina a $100 \mathrm{mM}$ para a realização da lise.

As células foram lisadas por sonicação, com os seguintes parâmetros: $30 \%$ de amplitude, intervalos de 4 segundos ON e 10 segundos OFF, durante 2 minutos. Após essa etapa, a suspensão foi centrifugada a $10.000 \mathrm{~g}$, por 5 minutos a $4{ }^{\circ} \mathrm{C}$. No sobrenadante estavam as proteínas solúveis, e no sedimento as proteínas insolúveis, e o sobrenadante foi liofilizado. Sendo assim, as duas fases foram analisadas uma vez por SDS-PAGE 15\%, para verificar em qual delas havia maior concentração da hemopressina.

\subsection{Quantificação do nível de expressão da hemopressina}

A quantificação do nível de expressão da hemopressina foi realizada por densitometria. Para tanto, durante a expressão, foram retiradas alíquotas de $1 \mathrm{~mL}$ no momento em que as células atingiram valores de absorbância (OD600) entre 0,6 a 0,8; sendo este o tempo zero ou seja, o não induzido. Após a indução com IPTG, foram retiradas alíquotas de 1 hora, 2 horas, 3 horas, 4 horas, 5 horas e over night (22 horas), após a indução. As amostras foram centrifugadas a $4000 \mathrm{rpm}, 10$ minutos a $25{ }^{\circ} \mathrm{C}$; o sobrenadante foi descartado e ao sedimento foram adicionados $100 \mu \mathrm{L}$ de tampão de amostra (4X) (glicerol 10\%, 2-mercaptoetanol 10\%, SDS (dodecil sulfato de sódio) 2,3\%, Tris $124 \mathrm{mM}$, azul de bromofenol 0,01\%), foram vortexadas e em seguida fervidas por 10 minutos. Foram aplicados $5 \mu \mathrm{L}$ de amostra em gel de SDS-PAGE 15\% (SAMBROOK \& RUSSELL, 2006).

Como amostra padrão, para auxiliar na quantificação, foi aplicada a albumina sérica bovina (BSA) nas concentrações de $1 \mu \mathrm{g}, 2 \mu \mathrm{g}$ e $5 \mu \mathrm{g}$. A migração das amostras ocorreu a $15 \mathrm{~mA}$ no gel concentrador e a $20 \mathrm{~mA}$ no gel separador, e o marcador de peso molecular BenchMark Protein Ladder (Invitrogen). O gel foi corado com Coomassie blue e em seguida descorado com solução descorante. A análise por densitometria ocorreu por meio da utilização do scanner ImageScanner III (GE) e pelo software 
Image Master 2D Platinum (G.E. Health Care). Para a detecção das bandas foram utilizados os seguintes parâmetros: "smooth": 2; saliência: 200; área mínima: 4.

\subsection{Confirmação da expressão da hemopressina fusionada a GST por Western Blot}

Nesta etapa, foram analisadas as seguintes amostras: hemopressina fusionada à GST, expressão em E. coli não transformada (controle negativo) e expressão em E. coli transformada com o vetor pGEX contendo apenas a proteína GST (controle positivo); todas elas foram expressas em meio de cultivo LB a $25^{\circ} \mathrm{C}$, induzido por IPTG na concentração de 0,25 mM quando as células atingiram absorbância (OD600) entre 0,6 a 0,8 .

Foram retiradas alíquotas de $1 \mathrm{~mL}$ a partir de 4 horas de indução. Essas foram centrifugadas a $4000 \mathrm{rpm}, 10$ minutos a $25^{\circ} \mathrm{C}$; o sobrenadante foi descartado e ao sedimento foi adicionado um volume de $100 \mu \mathrm{L}$ de tampão de amostra (4X) (glicerol 10\%, 2-mercaptoetanol 10\%, SDS (dodecilsulfato de sódio) 2,3\%, Tris $124 \mathrm{mM}$, azul de bromofenol $0,01 \%$ ). As amostras foram vortexadas e em seguida fervidas por 10 minutos.

Foram aplicados $2 \mu \mathrm{L}$ de amostra em géis de SDS-PAGE 15\% (SAMBROOK \& RUSSELL, 2006). Um gel foi transferido para uma membrana (membrane optimized for protein transfer - GE) e outro funcionou como espelho do gel transferido. Para a corrida dos géis foi utilizado o sistema de eletroforese Bio-Rad (cat. ${ }^{\circ} 165-8003$ ), gel de 8,6 X $6,8 \mathrm{~cm}, 75 \mathrm{~mm}$. No preparo para a transferência, o gel e a membrana foram tratados com tampão de ativação ou tampão de transferência (Tris base 25 mM, glicina 192 mM, metanol 20\%) por 10 minutos. Em seguida as amostras foram transferidas para a membrana com o auxílio do sistema de transferência Trans-Blot SD Semi-Dry Transfer Cell (Bio-Rad), a $5 \mathrm{~V}$ por 22 minutos.

Após a transferência, a membrana foi incubada com solução de bloqueio TBS 1X (Tris-HCl 20 mM, NaCl 150 mM, pH 7,5; mais 5\% de leite em pó) over night. Após este período, a membrana foi lavada 3 vezes com tampão de lavagem (TBS-T) (TBS 1X mais $0,05 \%$ de Tween) e incubada com anticorpo primário anti-GST (GE) produzido em cabra, na diluição de 1:5000, por um período de 3 horas. Após essa etapa, a membrana foi lavada três vezes com tampão de lavagem TBS-T (TBS $1 \mathrm{X}$ mais $0,05 \%$ de Tween) e incubada com o anticorpo secundário anti-cabra conjugado à fosfatase 
alcalina (ref. A4187, Sigma), na proporção de 1:5000 por um período de três horas. Em seguida, a membrana foi lavada três vezes com tampão de lavagem e logo adicionada à solução de revelação (Alkaline Phosphatase Conjugate Substrate Kit, Bio-Rad).

\subsection{Purificação da hemopressina recombinante}

Após as etapas de expressão e sonicação da proteína, o meio de expressão foi centrifugado e a fração solúvel conservada, conforme descrito anteriormente. Este volume, por sua vez, foi liofilizado e posteriormente utilizado na purificação. Desta forma, dois mililitros de resina Glutathione Sepharose 4 Fast Flow (GE) foram inseridos em coluna (Bio-Rad, $10 \mathrm{~mL}$ ) e foi ligada a uma bomba peristáltica (Pump P-1, GE) com fluxo de $1 \mathrm{~mL} / \mathrm{min}$. O peptídeo hemopressina fusionado à GST foi purificado por cromatografia de afinidade seguindo instruções do fabricante. A ativação e lavagem da coluna foram realizadas com PBS 1X; e a eluição da hemopressina foi conduzida com tampão de eluição (Tris 50 mM, glutathiona reduzida, pH 8.0).

\subsection{Síntese dos peptídeos em fase sólida e sequenciamento}

A produção das hemopressinas sintéticas foi realizada a partir da síntese manual, utilizando a metodologia de síntese de peptídeo em fase sólida, via estratégia 9fluorenilmetoxicarbonilo (Fmoc), na escala de síntese de 0,4 mmol, seguindo o protocolo de acoplamento HBTU/DIPEA. Para a síntese da hemopressina de humano (PVNFKLLSH) utilizou-se a resina Fmoc-His(Trt)-Wang Resin (100-200 mesh) 1\% DVB (Peptides International). Já para a hemopressina de murino (PVNFKFLSH) utilizou-se a resina His(Trt)-2-ClTrt-Resin (100-200 mesh) 1\% DVB (Peptides International).

Nas etapas de acoplamento (que consiste na formação de ligação amida entre dois aminoácidos), foram adicionados sequencialmente os aminoácidos no sentido de Cterminal para N-terminal. Dessa forma, em cada etapa foi adicionado Fmoc-AA (4 equivalentes ou vezes escala de síntese); HBTU (4 equivalentes ou vezes escala de síntese, Novabiochem) e DIPEA ( $N, N$-diisopropiletilamina) (7,6 equivalentes ou 7,6 vezes a escala de síntese, $170 \mu \mathrm{L} \mathrm{mmol}{ }^{-1}$ ) como agentes ativadores do grupamento carboxílico e DMF (N,N-dimetilformamida, Vetec) (entre 1 a $3 \mathrm{~mL}$ ) como solvente. A 
mistura reacional foi submetido à agitação orbital, temperatura ambiente, com tempo de duração da reação de 1 hora.

Após cada acoplamento, foi realizada a etapa de desproteção, que consiste na remoção dos grupos protetores Fmoc para possibilitar a adição do derivado de aminoácido seguinte. Desta forma, foram realizadas duas incubações de 15 minutos cada, temperatura ambiente sob agitação orbital, com solução a $25 \%$ de 4metilpiperidina em DMF. Em seguida, foram realizadas lavagens sequenciais da resina, com DMF (Synth) e 2-propanol, seguidas por uma lavagem final com diclorometano (DCM, Dinâmica).

A eficiência de cada acoplamento foi avaliada utilizando o teste de Kaiser, o qual é um teste químico qualitativo que indica grupo amino livre (TROLL e CANNAN, 1953). Este teste é composto por soluções de piridina a $2 \%$ (v/v) em solução aquosa de $\mathrm{KCN}$ a $1 \mathrm{M}$, fenol a $80 \%(\mathrm{~m} / \mathrm{v})$ em etanol e ninhidrina a $5 \%(\mathrm{~m} / \mathrm{v})$ em piridina, nas proporções 1:2:1 (v:v:v) e nesta ordem.

Ao final da síntese, foi realizada a reação de clivagem (remoção do peptídeo da resina) e a remoção dos grupos protetores das cadeias laterais. Para isto, a resina foi seca à pressão reduzida por cerca de 1 hora. Em seguida, ela foi pesada e transferida para um tubo Falcon (polipropileno) de $50 \mathrm{~mL}$, ao qual foi adicionada uma mistura composta por $95 \%$ de ácido trifluoracético (TFA), 2,5\% de água e 2,5\% de triisopropilisilano (TIS). O TFA é responsável pela remoção da ligação CO-resina e dos grupos protetores. Contudo, seu uso favorece a formação de carbocátions. Sendo assim, utiliza-se o TIS para efetuar a captura dos carbocátions (CHAN e WHITE, 2000). A resina com esta mistura reacional foi homogeneizada com auxílio de um agitador magnético, à temperatura ambiente, por 90 minutos. Em seguida, a solução foi evaporada com uso de nitrogênio gasoso. O sedimento (peptídeo) formado no fundo do Falcon foi precipitado com éter di-isopropílico gelado sob $\mathrm{N}_{2}$ líquido e filtrado. Sendo assim, o peptídeo que havia ficado retido no filtro, foi solubilizado em água ultrapura e submetido à liofilização.

As sequências de aminoácidos de ambas as formas da hemopressina foram confirmadas por espectrometria de massa MALDI no modo LIFT $^{\mathrm{TM}}$ em um equipamento AutoflexSpeed (Bruker Daltonics, Bilerica, MA, EUA), o qual confirmou que os peptídeos foram sintetizados corretamente. 


\subsection{Purificação das hemopressinas sintéticas por Cromatografia Líquida de Alto Desempenho}

A purificação dos peptídeos sintéticos foi realizada por cromatografia de fase reversa (Shimadzu LC-20AT) numa coluna semi preparativa C18 (Jupiter $5 \mu \mathrm{m}, 250 \mathrm{x}$ $10 \mathrm{~mm}, 300 \AA$ A), no fluxo de $1 \mathrm{~mL} / \mathrm{min}$ e a fase móvel composta por acetonitrila/ácido trifluoracético 0,1\% (Sigma, St Louis, MO, EUA) e água/ácido trifluoracético 0,1\%. O gradiente de acetonitrila $(\mathrm{ACN})$ de 5 a $95 \%$, fluxo de $1 \mathrm{~mL} / \mathrm{min}$, temperatura ambiente. A absorbância foi monitorada em $254 \mathrm{~nm}$. Para a purificação de cada amostra, em cada corrida foram aplicados 2,0 mg do produto bruto de síntese, o qual foi solubilizado em $500 \mu \mathrm{L}$ de Água/Ácido trifluoracético $0,1 \%$ e filtrado em filtro 0,45 $\mu \mathrm{m}$ (Millex®-HA SyringeDrivenFilter Unit, ref. SLHA 025 NB, Millipore). A pureza e a homogeneidade dos peptídeos sintéticos foram determinadas por espectrometria de massa. 


\section{RESULTADOS E DISCUSSÃO}

\subsection{Produção da hemopressina recombinante}

Visando a desenvolver uma metodologia de produção inicial em pequena escala da hemopressina recombinante, a sequência codificadora do peptídeo hemopressina foi sintetizada no vetor de expressão pGEX-4T-1, contendo o gene de indução para IPTG e o tag GST. O sistema de expressão utilizado para a produção da hemopressina foi bacteriano, especificamente E. coli. A escolha por este sistema deu-se pela sua caracterização genética bem definida, por apresentar rápido crescimento celular, rendimento elevado de expressão e por ser o sistema mais indicado para proteínas não glicosiladas (CHOU et al., 2007; HUANG et al., 2012).

A produção da hemopressina fusionada à proteína GST teve como objetivo facilitar a identificação e a purificação do peptídeo expresso, visto que a proteína GST apresenta afinidade pela resina Glutationa Sepharose, permitindo assim, o seu uso na purificação. Os tags são amplamente usados na expressão recombinante de proteínas, visando a aumentar a eficiência de iniciação da tradução, ajudar no enovelamento e prevenir a proteólise, possibilitando a obtenção da molécula na forma ativa (ROSANO \& CECCARELLI, 2014). Em E. coli o uso de proteínas de fusão proporciona melhor solubilidade às proteínas expressas, além de simplificar o processo de purificação (LEBENDIKER \& DANIELI, 2014). A glutationa S-transferase (GST) está entre as proteínas de fusão mais potentes quanto à solubilidade (ZOU et al., 2008).

A expressão da hemopressina fusionada à GST foi confirmada por Western blot usando anticorpo anti-GST. Para essa análise, foram aplicados $2 \mu \mathrm{L}$ da alíquota de proteína total da expressão. O resultado demonstrou a presença do peptídeo fusionado (Figura 2) no tamanho esperado de 31,11 kDa. 

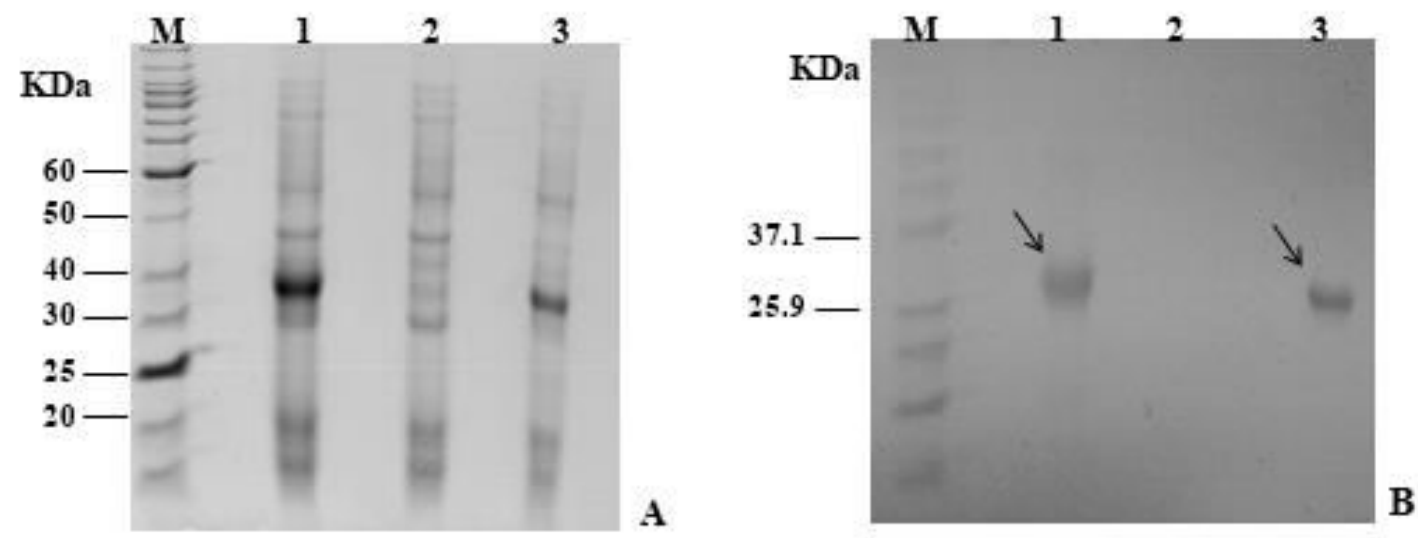

Figura 2- SDS-PAGE e Western blotting do extrato proteico da expressão da hemopressina em E. coli. A. SDS-PAGE do extrato proteico da expressão da hemopressina em E. coli. M: Marcador de peso molecular BenchMark ${ }^{\mathrm{TM}}$ UnstainedProteinLadder (Invitrogen). 1: hemopressina fusionada à GST após 4 horas de expressão em meio de cultivo LB a $25^{\circ} \mathrm{C}$, induzido por IPTG na concentração de $0,25 \mathrm{mM}$. Em 2, expressão em $E$. coli não transformada. 3: Expressão de GST em $E$. coli após 4 horas em meio de cultivo LB a $25{ }^{\circ} \mathrm{C}$, induzido por IPTG na concentração de $0,25 \mathrm{mM}$. B. Western blotting do extrato proteico da expressão da hemopressina em E. coli. M: Marcador de peso molecular BenchMark ${ }^{\mathrm{TM}}$ Prestained ProteinLadder (Invitrogen) .

\subsection{Quantificação do nível de expressão de hemopressina recombinante}

A determinação das melhores condições de expressão de uma proteína é um passo extremamente importante e desafiante, pois visa a otimizar tempo, custo, rendimento e atividade. Sendo assim, na determinação do perfil de expressão da hemopressina foram avaliados alguns parâmetros, tais como meio de cultivo, temperatura, concentração do indutor e tempo de expressão após a indução. Desta forma, foram avaliadas expressões realizadas utilizando os meios de cultivo LB e 4YT, sob temperaturas de $15{ }^{\circ} \mathrm{C}, 20^{\circ} \mathrm{C}, 25^{\circ} \mathrm{C}, 30^{\circ} \mathrm{C}$ e $37^{\circ} \mathrm{C}$, com concentrações do indutor de expressão IPTG a 0,25 mM, 0,5 mM e $1 \mathrm{mM}$; e tempos de expressão de 0 a 5 horas e durante a noite (não mostrado), após a indução (Figura 3). 


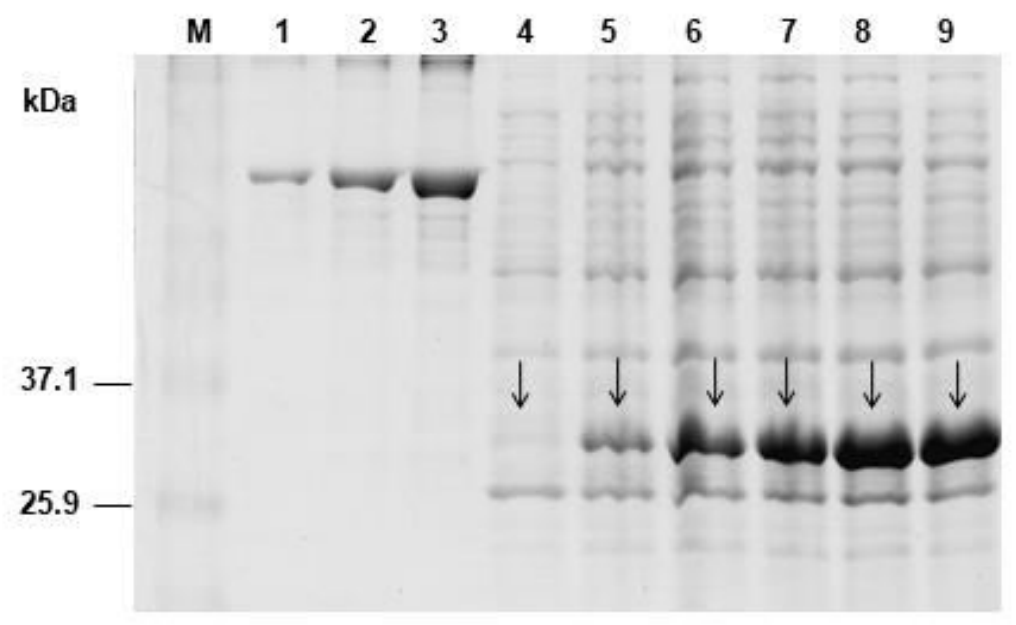

Figura 3. SDS-PAGE do extrato proteico da expressão da hemopressina fusionada a GST, em E. coli. Como padrão, foram utilizados $1.0 \mu \mathrm{g}$ (1), $2.0 \mu \mathrm{g}$ (2) e $5.0 \mu \mathrm{g}$ (3) de BSA. M: Marcador de peso molecular BenchMark ${ }^{\mathrm{TM}}$ Prestained Protein Ladder (Invitrogen). 4: expressão de hemopressina não induzida por IPTG. 5, 6, 7, 8, 9: hemopressina induzida por IPTG na concentração de 0,25 mM, após 1, 2, 3,4 e 5 horas de expressão em meio de cultivo $\mathrm{LB}$ a $25^{\circ} \mathrm{C}$, respectivamente.

Foi observado maior nível de expressão da hemopressina, utilizando meio LB, na temperatura de $25^{\circ} \mathrm{C}$, a $0,25 \mathrm{mM}$ do indutor IPTG e 4 horas de expressão após a indução (Tabela 3). O rendimento da expressão foi calculado em 147,8 mg/L do peptídeo fusionado a GST, em extrato total de proteínas (Figura 4), sendo a maior parte da expressão da hemopressina encontrada na fração solúvel.

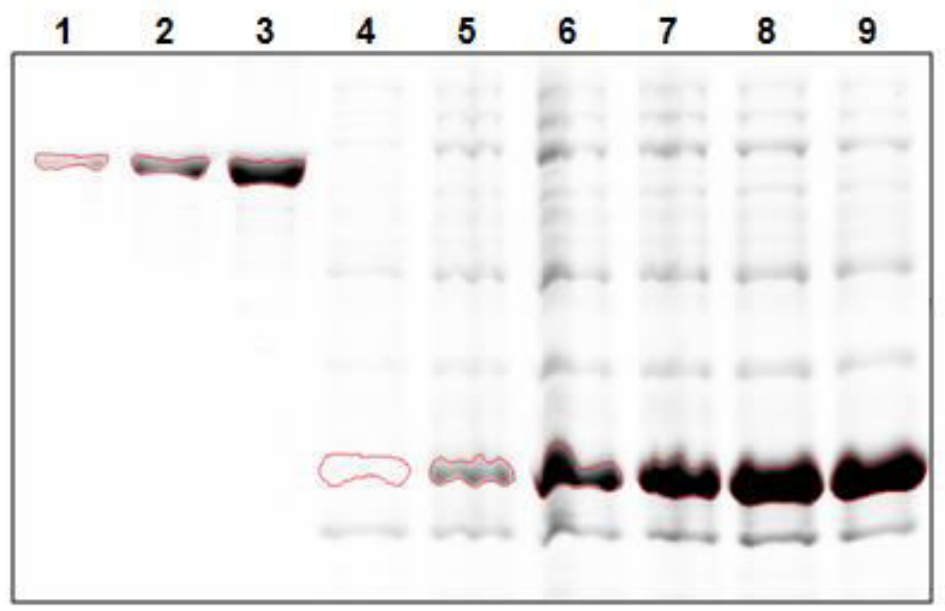

Figura 4. Quantificação por densitometria do extrato proteico da expressão da hemopressina fusionada a GST, em E. coli.Como padrão, foram utilizados $1.0 \mu \mathrm{g}$ (1), $2.0 \mu \mathrm{g}$ (2) e $5.0 \mu \mathrm{g}$ (3) de BSA. M: Marcador de peso molecular BenchMark ${ }^{\mathrm{TM}}$ Prestained Protein Ladder (Invitrogen). 4: expressão de hemopressina não induzida por IPTG. 5, 6, 7, 8, 9: hemopressina induzida por IPTG na concentração de $0,25 \mathrm{mM}$, após $1,2,3,4$ e 5 horas de expressão em meio de cultivo $\mathrm{LB}$ a $25^{\circ} \mathrm{C}$, respectivamente. 
Tabela 3. Parâmetros gerais e de maior expressão da hemopressina

\begin{tabular}{|c|c|c|c|c|c|}
\hline Meio de & Temperatura & \multicolumn{4}{|c|}{ Concentração do Indutor (mM) } \\
\hline \multirow{5}{*}{ LB } & 15 & 0 & 0,25 & 0,5 & 1 \\
\hline & 20 & 0 & 0,25 & 0,5 & 1 \\
\hline & 25 & 0 & 0,25 & 0,5 & 1 \\
\hline & 30 & 0 & 0,25 & 0,5 & 1 \\
\hline & 37 & 0 & 0,25 & 0,5 & 1 \\
\hline \multirow{5}{*}{$4 \mathrm{YT}$} & 15 & 0 & 0,25 & 0,5 & 1 \\
\hline & 20 & 0 & 0,25 & 0,5 & 1 \\
\hline & 25 & 0 & 0,25 & 0,5 & 1 \\
\hline & 30 & 0 & 0,25 & 0,5 & 1 \\
\hline & 37 & 0 & 0,25 & 0,5 & 1 \\
\hline
\end{tabular}

* O parâmetro que levou à maior produção do peptídeo recombinante encontra-se marcado em cinza.

Assim como na expressão da hemopressina, Yu et al. (2013), utilizaram o vetor de expressão pGEX-4T-1, contendo o tag GST (glutationa S-transferase), para a expressão recombinante de uma molécula humana, FHL2. Também nesse estudo, foram avaliados diversos parâmetros de otimização do nível de expressão, tais como concentração do indutor IPTG, tempo de expressão após a indução e temperatura. Contudo, a maior parte da expressão de GST-FHL2 estava na forma de corpos de inclusão em temperaturas mais elevadas. Mas quando expressa sob temperatura menor, a $23{ }^{\circ} \mathrm{C}$, cerca de $50 \%$ da proteína expressa estava na forma solúvel, mostrando que a escolha da temperatura também pode minimizar esse efeito indesejável. Yu e 
colaboradores obtiveram melhores níveis de expressão a $23{ }^{\circ} \mathrm{C}$, uma temperatura próxima da temperatura ótima de expressão da hemopressina $\left(25^{\circ} \mathrm{C}\right)$.

Li et al. (2014) utilizaram o vetor pGEX-4T-1 e o tag GST, na expressão das moléculas Granzima B (GrB) e perforina (PFP), as quais parecem ter envolvimento na supressão da progressão tumoral. Os autores obtiveram rendimento de 10,5 e 4,3 mg/0,5 L de meio de cultivo, de GST-GrB e GST-PFP purificadas, respectivamente.

A importância do tag na solubilização da molécula pode ser reforçada pelo trabalho de Nguyen et al. (2014), na expressão recombinante em E. coli, do hormônio do crescimento humano (hGH). Como este hormônio tende a agregar-se e a formar corpos de inclusão, afetando a sua solubilidade, foram avaliadas a expressão do hGH, testando sete diferentes tags. Foi demonstrado que as tags MBP (maltose-binding protein) e PDI (protein disulfide bond isomerase) aumentaram significativamente a solubilidade do hormônio. Além disso, o produto expresso sob temperatura menor, a 18 ${ }^{\circ} \mathrm{C}$, também apresentou melhor solubilidade, em todas as proteínas de fusão avaliadas, mostrando que, a temperatura é um parâmetro importante também quanto à solubilidade da molécula expressa.

Basso et al. (2015) realizaram a expressão recombinante do peptídeo glucagon em E. coli. Para isso, utilizaram o vetor de expressão pGEX-4T-3, proteína de fusão GST e indutor IPTG. Nesse estudo, o melhor nível de expressão foi obtido sob temperatura de $30{ }^{\circ} \mathrm{C}$, a $0,25 \mathrm{mM}$ de IPTG e 4 horas de expressão após a indução, apresentando rendimento de 40 a 50\% de GST-glucagon da expressão total de proteínas. Os melhores parâmetros de expressão obtidos nesse estudo foram iguais aos da produção da hemopressina, exceto a temperatura. A hemopressina foi melhor expressa a $25^{\circ} \mathrm{C}$, temperatura ainda menor que na produção do glucagon. Expressão heteróloga em temperaturas reduzidas é um fator positivo para minimização de atividades de peptidases, de agregação e formação de corpos de inclusão.

A hemopressina também demonstrou melhores condições de expressão quando comparadas com a otimização para expressão de KGLP-1, um análogo do peptídeo glucagon tipo 1 (GLP-1), realizado por Liu et al. (2014). No estudo dos autores, foi utilizado o plasmídeo de expressão pET-GST-3C (contendo o tag GST), sistema em $E$. coli, e expressão durante seis horas, induzida com IPTG na temperatura de $37{ }^{\circ} \mathrm{C}$. O rendimento de KGLP-1 purificado foi de aproximadamente $12,1 \mathrm{mg} / \mathrm{L}$. Tendo em vista que a hemopressina apresentou melhor rendimento a $25^{\circ} \mathrm{C}$, e com 4 horas de expressão, deve-se considerar que expressão a temperaturas reduzidas é um fator positivo devido à 
minimização da proteólise. Além disso, menor tempo de expressão significa redução no custo da produção.

De acordo com os protocolos padrão de purificação de proteínas recombinantes por técnicas cromatográficas (HANDBOOK, 2001) em torno de $80 \%$ do material purificado pode ser recuperado quando se utiliza apenas um passo cromatográfico. Aplicando isto ao rendimento de expressão da hemopressina $(147,8 \mathrm{mg} / \mathrm{L})$, seria esperado recuperar cerca de $120 \mathrm{mg}$ do peptídeo recombinante fusionado à GST por litro de meio de expressão. Esta quantidade encontra-se bem acima do descrito por Nguyen e colaboradores ( 37 e $12 \mathrm{mg} / 0,5 \mathrm{~L})$, Liu e colaboradores $(12,1 \mathrm{mg} / \mathrm{L})$, Li e colaboradores (10,5 e 4,3 mg/0,5 L).

Os trabalhos citados comprovam a importância da avaliação e determinação dos melhores parâmetros para produção de um peptídeo ou proteína, tais como o uso de tag, temperatura de expressão, concentração do indutor. Além disso, vários desses estudos demonstraram o uso das mesmas ferramentas e condições utilizadas na produção recombinante da hemopressina, tais como o sistema de expressão em E. coli, vetor de expressão pGEX, a proteína de fusão GST, indutor IPTG e temperatura inferior a $37^{\circ} \mathrm{C}$. A hemopressina demonstrou maior rendimento na expressão a $25{ }^{\circ} \mathrm{C}$, durante quatro horas após a indução, utilizando IPTG na concentração de 0,25 mM. A baixa concentração do indutor favorece menor custo na produção, e ainda, conforme Pacheco et al. (2012), auxilia na solubilidade da proteína, por gerar menor estresse para a célula bacteriana. De fato, a hemopressina não apresentou problemas na solubilização.

\subsection{Purificação da hemopressina fusionada à GST por cromatografia de afinidade}

A purificação é uma etapa extremamente importante juntamente ao processo de expressão de peptídeos e proteínas recombinantes. Composta por vários processos que visam ao isolamento de uma molécula de uma mistura, a purificação possibilita realizar a caracterização da estrutura, função e interações do peptídeo ou proteína de interesse. Desta forma, na expressão de peptídeos, é extremamente importante a fusão de tags a essas moléculas, para auxiliar no processo de purificação. Neste trabalho, a hemopressina foi fusionada ao tag GST, o qual apresenta afinidade à resina Glutathione Sepharose 4 Fast Flow (GE). Sendo assim, tal resina foi utilizada para purificação da hemopressina, por cromatografia de afinidade, no fluxo de $1 \mathrm{~mL}$ por minuto. Após a 
adição da proteína total, foram coletadas alíquotas de $1 \mathrm{~mL}$ do lavado (tampão de lavagem - PBS) e do eluído (tampão de eluição) e analisadas em gel SDS-PAGE 15\% (Figura 5), demonstrando que a purificação ocorreu de forma satisfatória, tendo em vista que o procedimento permitiu a obtenção da molécula com aproximadamente $90 \%$ de grau de pureza, o mesmo valor obtido Basso et al. (2015), com o uso desta metodologia.

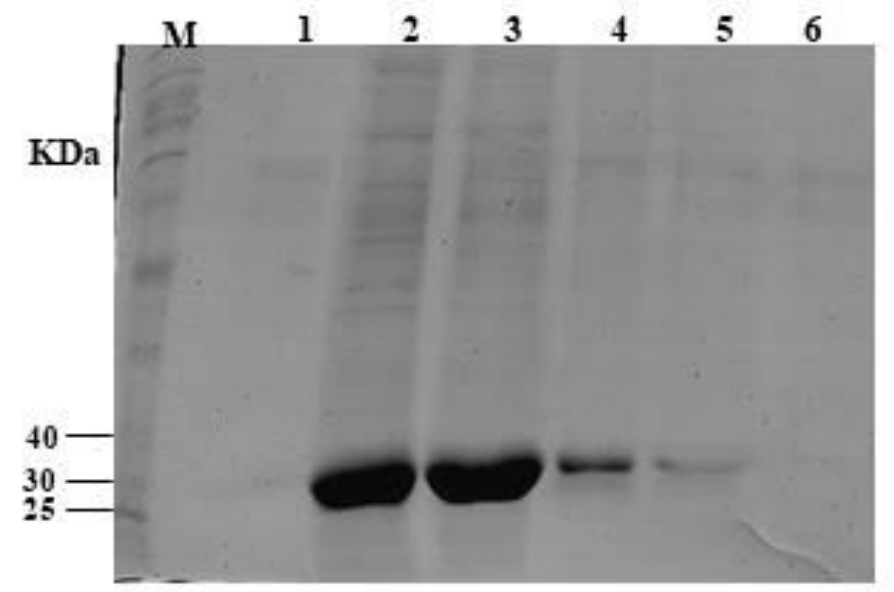

Figura 5- SDS-PAGE da hemopressina purificada por cromatografia de afinidade em resina Glutathione Sepharose 4 Fast Flow (GE). M: Marcador de peso molecular BenchMark ${ }^{\mathrm{TM}}$ UnstainedProteinLadder (Invitrogen). 1: primeiro mililitro de eluição da hemopressina fusionada à GST. 2: segundo mililitro de eluição da hemopressina fusionada à GST. 3: terceiro mililitro de eluição da hemopressina fusionada à GST. 4: quarto mililitro de eluição da hemopressina fusionada à GST. 5: quinto mililitro de eluição da hemopressina fusionada à GST. 6: sexto mililitro de eluição da hemopressina fusionada à GST.

Por análises iniciais, o uso do vetor pGEX-4T-1 e do tag GST demonstrou ser ideal para a produção da hemopressina, uma vez que proporcionou rendimento elevado da proteína GST-hemopressina, 147, $8 \mathrm{mg} / \mathrm{L}$. Além disso, tendo em vista que os tags são amplamente utilizados para auxiliar e simplificar os processos de identificação e purificação de peptídeos e proteínas fusionadas (GAO, 2010; WALLS \& LOUGHRAN, 2011), o uso da proteína de fusão GST na expressão da hemopressina, foi fundamental para identificar o peptídeo, uma vez que foi utilizado o anticorpo anti-GST. O uso do tag também possibilitou a purificação parcial, utilizando cromatografia de afinidade com o uso da resina glutathione sepharose. 


\subsection{Obtenção por síntese em fase sólida e sequenciamento das hemopressinas sintéticas}

Os peptídeos sintéticos foram obtidos por síntese química em fase sólida usando a estratégia Fmoc. Assim como neste trabalho, a hemopressina é amplamente produzida por essa estratégia e utilizada em ensaios de atividade, como nos estudos realizados por Rioli et al. (2003), Dale et al. (2005), Remelli et al. (2016).

Para confirmação da obtenção das hemopressinas de humano e de murino (Figura 6), foram realizadas análises por espectrometria de massa do produto bruto de sínteses dos peptídeos, demonstrando peptídeos com massa molecular de 1.054,6 Da e 1.088,6 Da, respectivamente.

A sequência de resíduos de aminoácidos da síntese da hemopressina humana foi confirmada por espectrometria de massa (Figura 7), no modo LIFT'M em um equipamento Autoflex Speed (Bruker Daltonics, Bilerica, USA).

Também após a confirmação da obtenção da hemopressina murina, as sequências de aminoácidos foram confirmadas por espectrometria de massa no modo LIFT ${ }^{\mathrm{TM}} \mathrm{em}$ um equipamento Autoflex Speed (Bruker Daltonics, Bilerica, USA), demonstrando a fragmentação do peptídeo com massa molecular de 1.088,6 Da (Figura 8). 


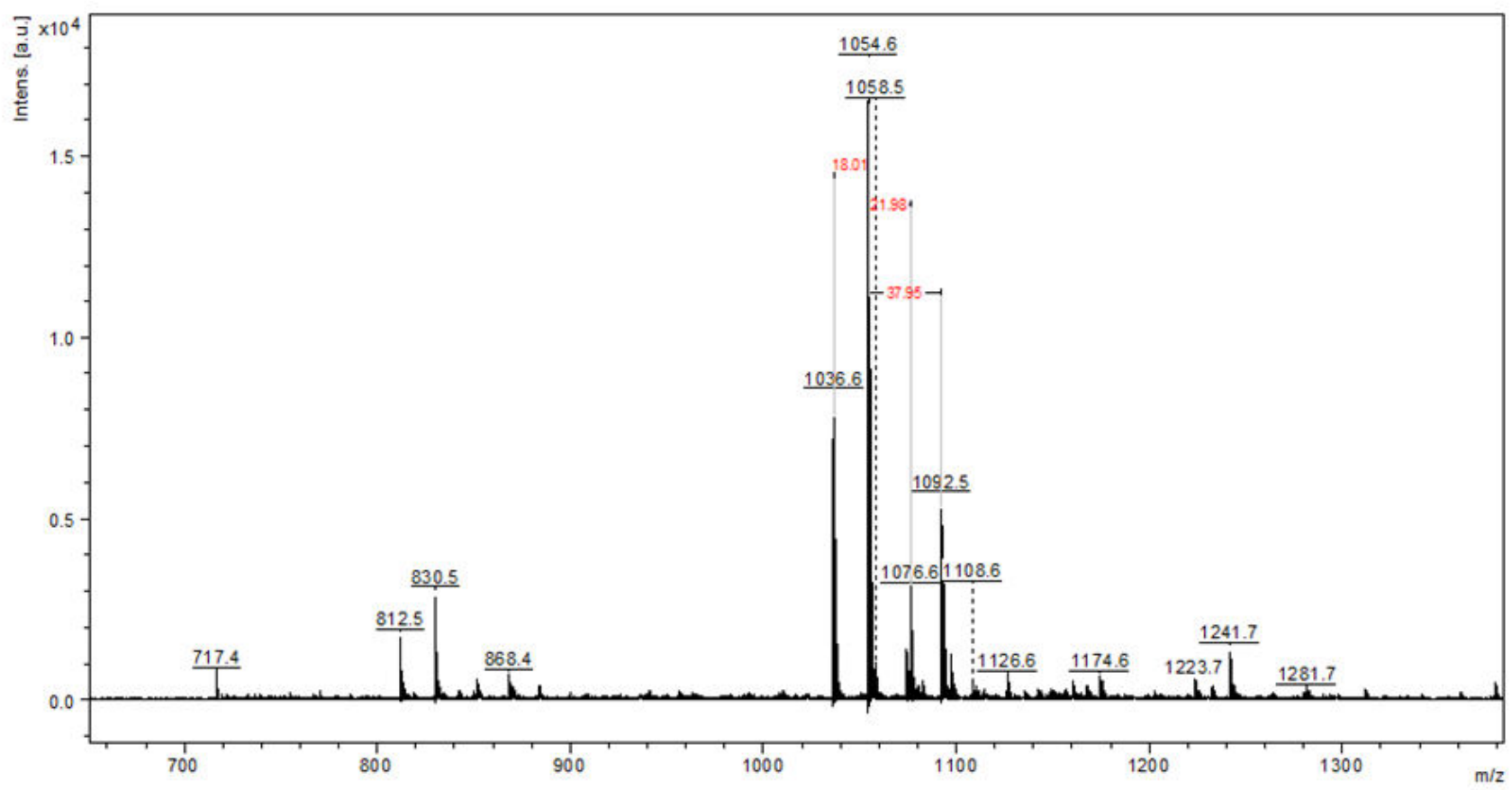

A

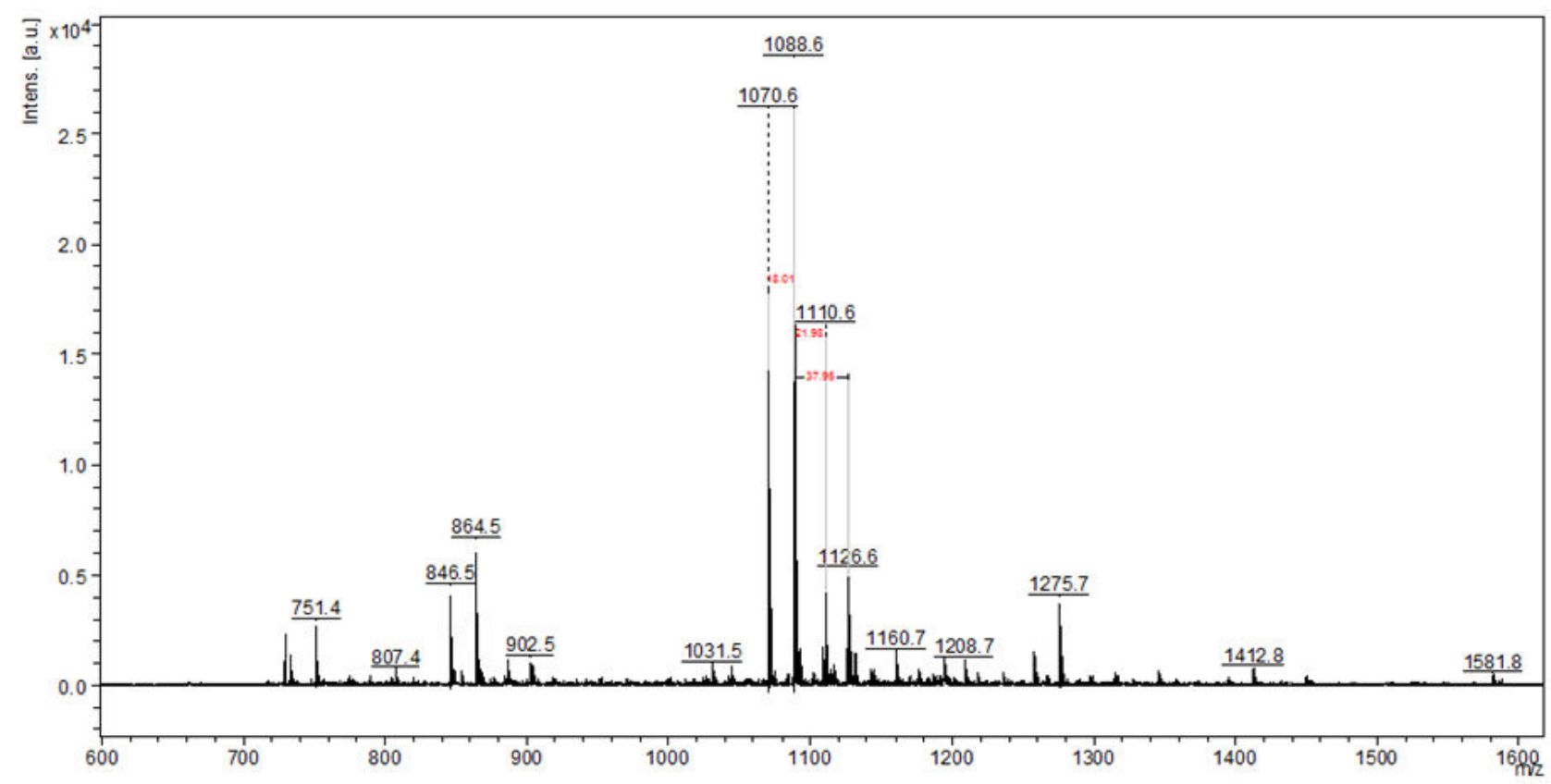

B

Figura 6. Espectros de massa dos produtos brutos de sínteses das hemopressinas. Hemopressina de origem humana (A) e do produto bruto de síntese da hemopressina murina (B). Os adutos de sódio e potássio, com diferenças de massa de 21.98 e 37.95, estão assinalados. A diferença de 18 unidades de massa e uma perda de $\mathrm{H}_{2} \mathrm{O}$ que ocorre na fonte de fragmentação do Maldi. Os espectros foram obtidos no modo positivo refletido no equipamento AutoflexSpeed (BrukerDaltonics, Bilerica, EUA) 


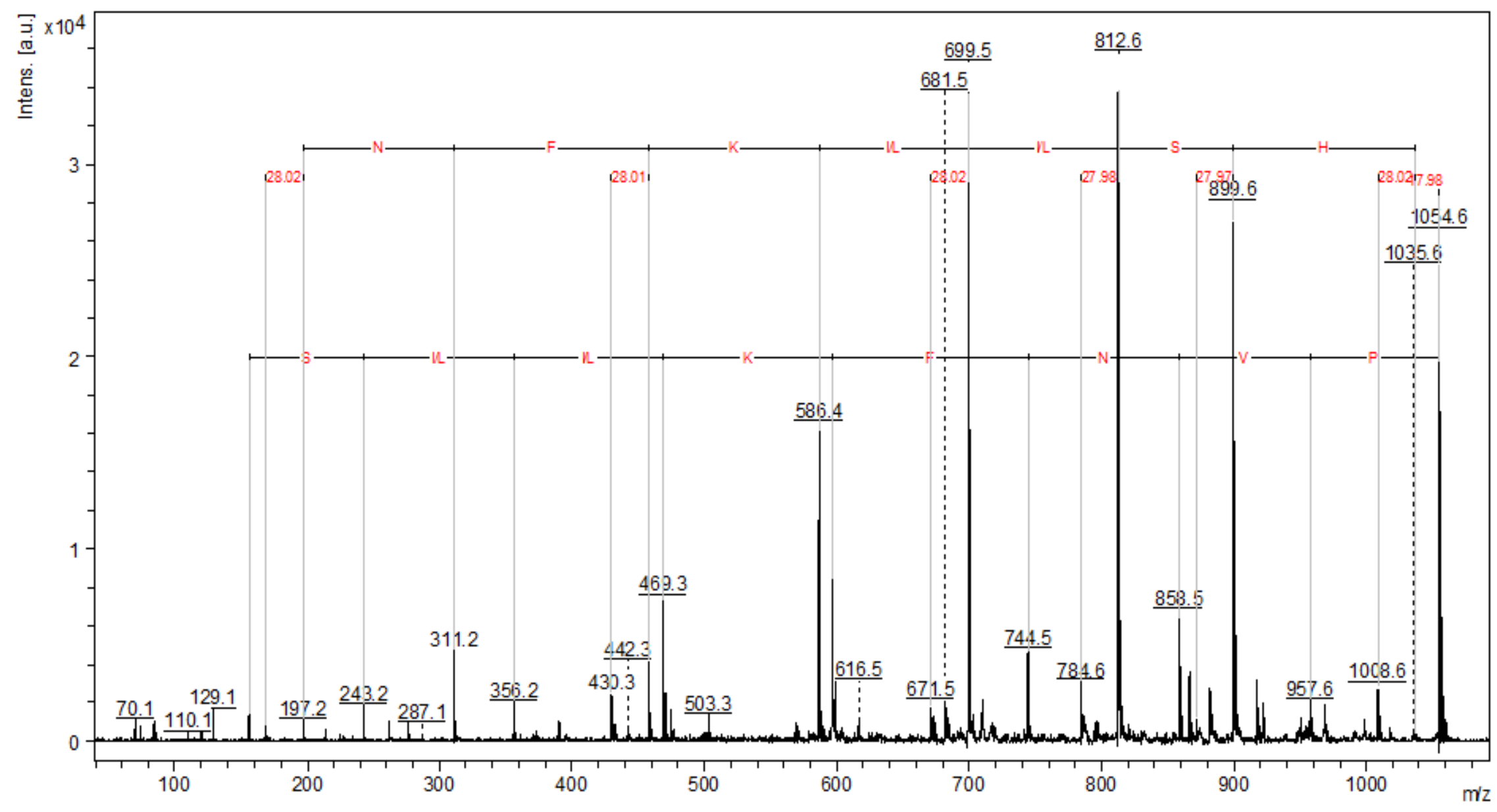

Figura 7. Espectro de fragmentação (MS/MS) do produto principal de síntese de hemopressina humana. $[M+H]^{+}=1054,6$. Sequência: PVNFKLLSH. Na parte superior está mostrada a série b e na parte inferior esta mostrada a série y. O espectro foi obtido no modo LIFT"M no equipamento Autoflex Speed (Bruker Daltonics, Bilerica, EUA). 


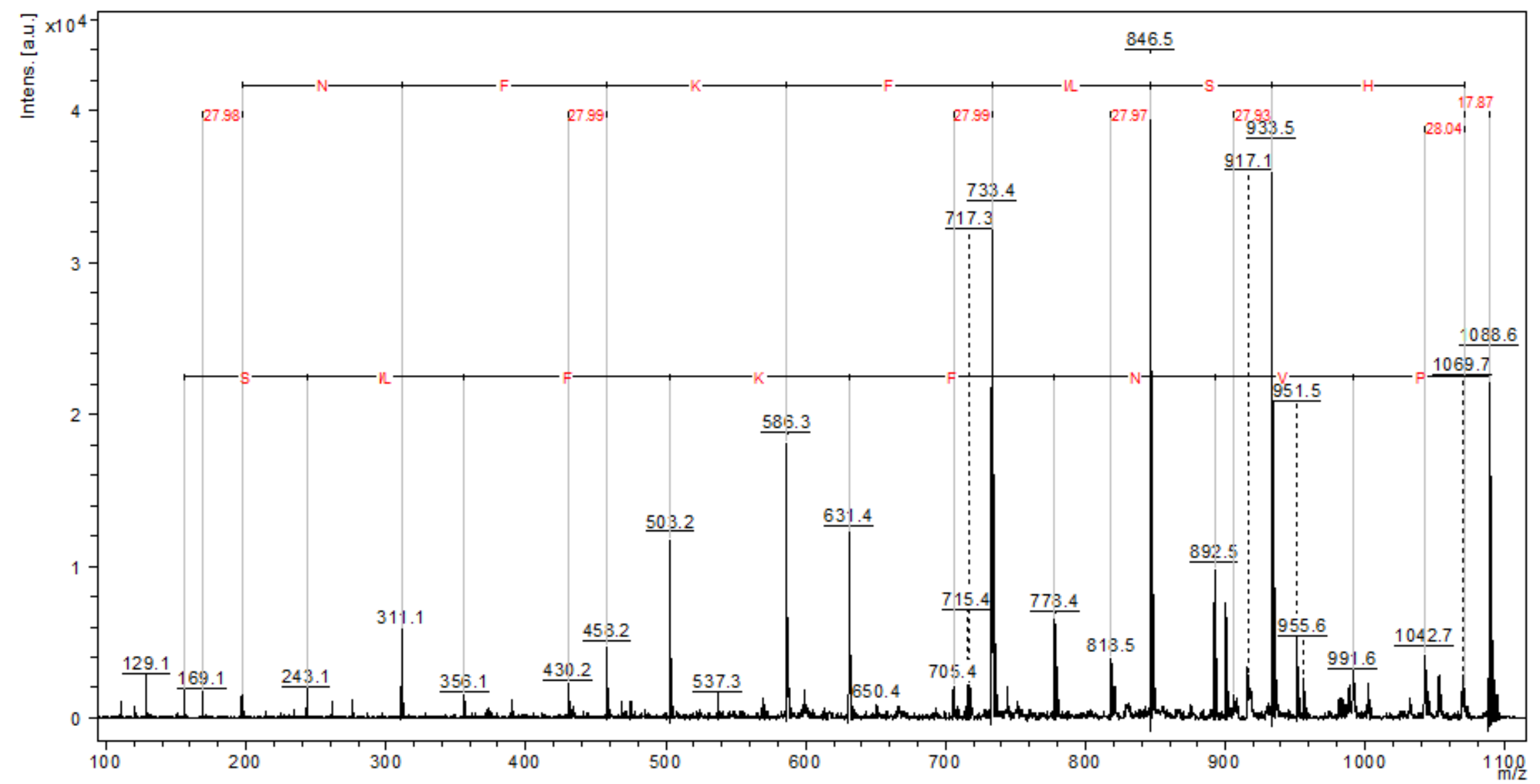

Figura 8. Espectro de fragmentação (MS/MS) do produto principal de síntese de hemopressina murina. $[\mathrm{M}+\mathrm{H}]^{+}=1088,6$. Sequência: PVNFKFLSH. Na parte superior está mostrada a série b e na parte inferior está mostrada a série y. O espectro foi obtido no modo LIFT TM no equipamento Autoflex Speed (Bruker Daltonics, Bilerica, EUA). 


\subsection{Purificação das hemopressinas sintéticas}

A qualidade de um medicamento peptídico é determinada principalmente pelo seu perfil de impurezas, tendo em vista que estas podem afetar a eficácia ou induzir a toxicidade do medicamento. Desta forma, autoridades reguladoras estabelecem especificações para garantir uma pureza consistente desses medicamentos (VAN DORPE et al., 2011). Também no âmbito de pesquisa biomédica, as impurezas podem apresentar maior afinidade de ligação em comparação ao peptídeo, provocando conclusões errôneas sobre os resultados (VERBEKE et al., 2015).

Após a síntese manual das hemopressinas sintéticas, estes peptídeos foram purificados por cromatografia líquida de alta eficiência (HPLC) em coluna de fase reversa. As hemopressinas de humano e de murino, foram eluídas em concentrações de aproximadamente $48 \%$ e $46 \%$ de acetonitrila, respectivamente (Figura 9). Este resultado é compatível com a maior hidrofobicidade do resíduo de leucina em relação ao resíduo aromático de fenilalanina.

A

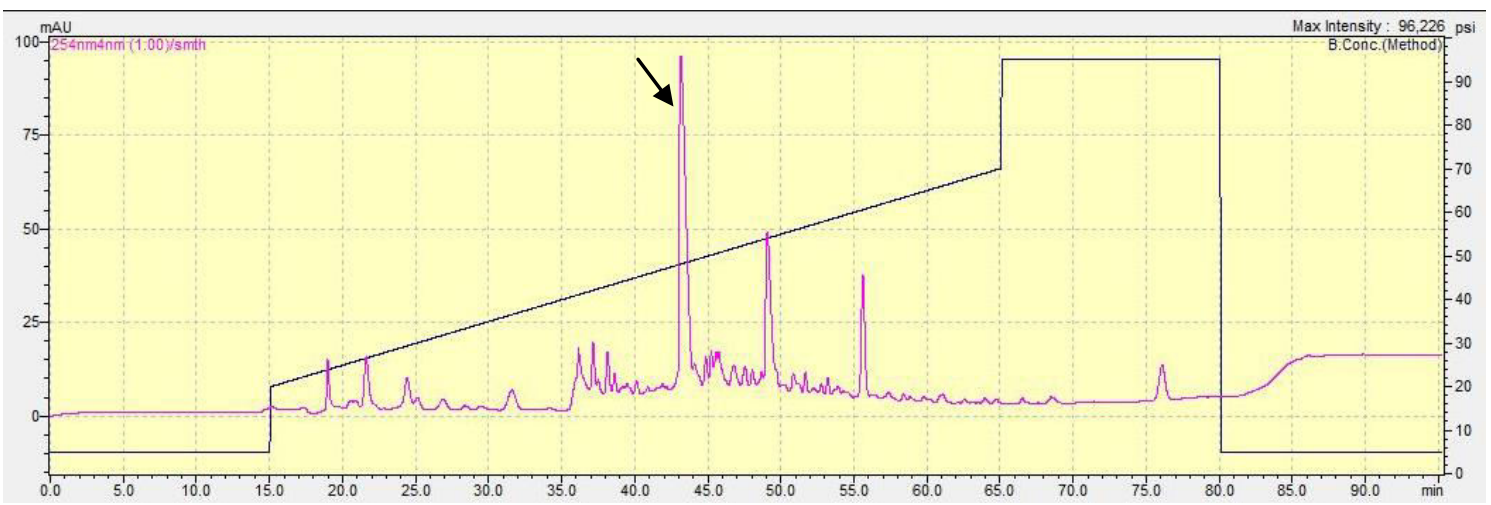

B

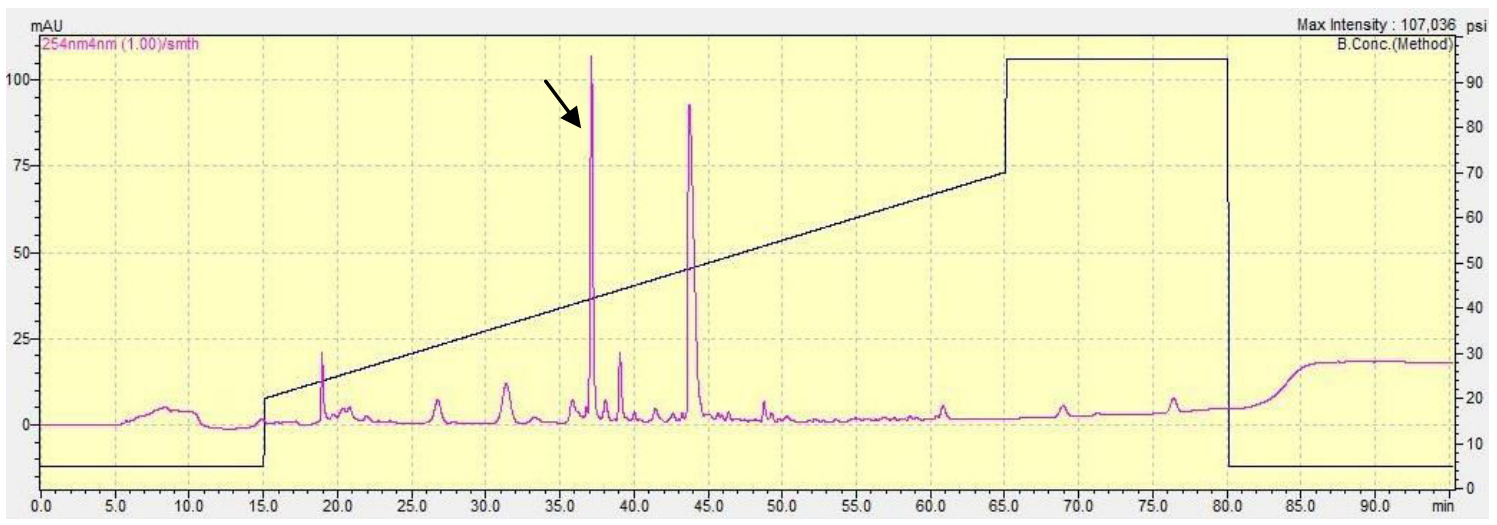

Figura 9. Purificação das hemopressinas sintéticas. A e B:Cromatogramas dos peptídeos Hp de humano e Hp de murino, respectivamente,eluídos em gradiente de acetonitrila ( $\mathrm{ACN})$ de $5-95 \%$ em coluna de fase reversa semipreparativa $\mathrm{C} 18(5 \mu \mathrm{m}, 250 \times 10 \mathrm{~mm})$, fluxo de $1 \mathrm{~mL} / \mathrm{min}$, utilizando sistema de cromatografia líquida de alta eficiência (HPLC). A absorbância foi monitorada em 254nm. 
A pureza e as massas moleculares dos peptídeos foram analisadas por espectrometria de massa (MALDI-TOF). Em cada espectro de massa apresentou, somente um pico de massa equivalente ao peptídeo avaliado. As massas moleculares para Hp de humano e Hp de murino foram de 1.054,6 Da e 1.088,6 Da, com graus de pureza de $\sim 95 \%$ e $97 \%$, respectivamente (Figura 10).
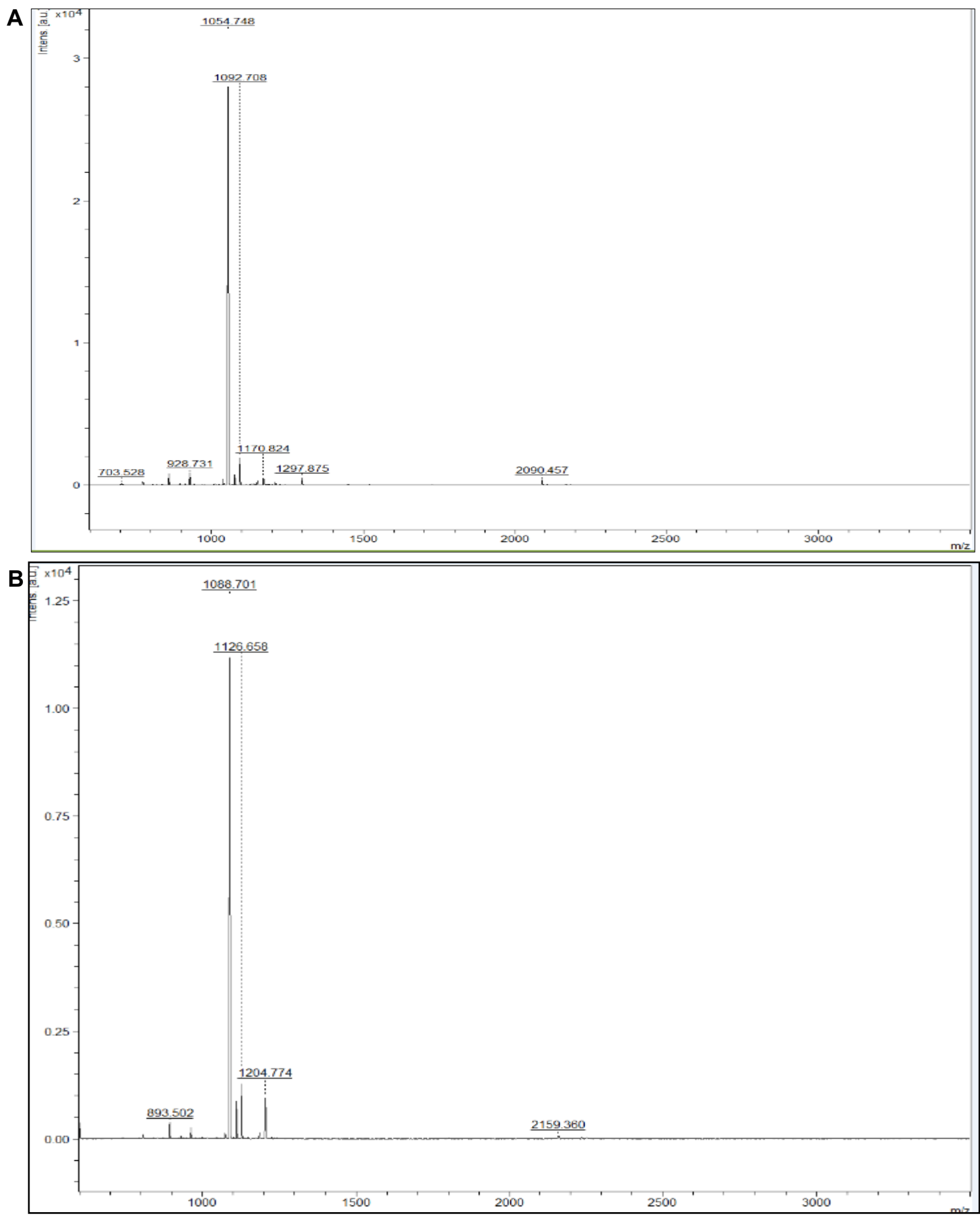

Figura 10. Espectros de massa das hemopressinas purificadas. Espectros de massa MALDI-TOF/MS representando a massa molecular $[\mathrm{M}+\mathrm{H}]+$ e o grau de pureza dos peptídeos Hp de humano (A) e Hp de murino (B). Os espectros foram obtidos no modo positivo refletido no equipamento Autoflex Speed (BrukerDaltonics, Bilerica, EUA). 
Tendo em vista que para consumo alimentar, uso clínico, realização de determinados ensaios biológicos e estudos estruturais ou de relação estrutura-atividade, são requeridos peptídeos com purezas iguais ou superiores a 95\% (MACHADO et al., 2004), as hemopressinas apresentaram pureza dentro do padrão exigido. 


\section{CONCLUSÃO}

Os dados obtidos nesse estudo permitem as seguintes conclusões:

As ferramentas (sistema de expressão em E. coli, vetor de expressão pGEX-4T1, tag GST), juntamente com os parâmetros de expressão determinados (temperatura, tempo de expressão, concentração do indutor), foram adequados para a obtenção do rendimento elevado do peptídeo hemopressina. As melhores condições de expressão foram obtidas de forma a proporcionar menor custo, sendo este, um fator essencial para o mercado farmacêutico.

Os peptídeos sintéticos apresentaram sequências corretas, conforme o esperado. Após a etapa de purificação, apresentaram alto grau de pureza, fator essencial para a obtenção de resultados confiáveis na avaliação em ensaios de pesquisa. Além disso, em âmbito clínico, a pureza do fármaco é um quesito obrigatório, exigido por unidades reguladoras competentes. 


\section{PERSPECTIVAS FUTURAS}

Atualmente, está sendo realizado o encapsulamento das hemopressinas sintéticas das formas humana e murina com PLGA, em colaboração com o Laboratório Ibérico Internacional de Nanotecnologia (INL), Braga-Portugal. As próximas etapas constituirão em realizar a clivagem do tag GST da hemopressina recombinante, realizar o seu encapsulamento com PLGA e avaliar as atividades in vitro e in vivo das hemopressinas recombinante e sintéticas, encapsuladas e não encapsuladas. 


\section{REFERÊNCIAS}

BAESHEN, M.N.; AL-HEJIN, A.M.; BORA, R.S.; AHMED, M.M.M.; RAMADAN, H.A.I.; SAINI, K.S.; BAESHEN, N.A.; REDWAN, E.M. Production of biopharmaceuticals in E. coli: Current scenario and future perspectives. Journal of Microbiology and Biotechnology. v.25, n.7, p.953-962, 2015.

BASSO, A.M.M.; PELEGRINI, P.B.; MULINARI, F.; COSTA, M.C.; VIANA, A.B.; SILVA, L.P.; GROSSI DE SÁ, M.F. Recombinant glucagon: a differential biological activity. AMB Express. v.5, n.20, p.1-9, 2015.

BEGG, M.; PACHER, P.; BATKAI, S.; OSEI-HYIAMAN, D.; OFFERTALER, L.; MO, F.M; LIU, J.; KUNOS, G. Evidence for novel cannabinoid receptors. Pharmacology \& Therapeutics. v.106, n.2, p.133-145, 2005.

BLAIS, P.A.; COTE, J.; MORIN, J.; LAROUCHE, A.; GENDRON, G.; FORTIER, A.; REGOLI, D.; NEUGEBAUER, W.; GOBEIL JR, F. Hypotensive effects of hemopressin and bradykinin in rabbits, rats and mice. A comparative study. Peptides. v.26, p.1317-1322, 2005.

BOMAR, M.G.; GALANDE, A.K. Modulation of the cannabinoid receptors by hemopressin peptides. Life Sciences. v.92, p.520-524, 2013.

BOYD, S.T. The endocannabinoid system. Pharmacotherapy. v.26, n.12, p. 218s-221s, 2006.

BRASIL. Lei de Inovação Tecnológica n. 10.973 de 2 de dezembro de 2004. Presidência da República, Casa Civil. Subchefia para Assuntos Jurídicos. 2004.

BRASIL. RELAÇÃO NACIONAL DE MEDICAMENTOS ESSENCIAIS 2017. Ministério da Saúde. Brasília-DF, 2017.

CARPINO, L.; HAN, G.Y. The 9-Fluorenylmethoxycarbonyl Amino-Protecting Group. Journal of Organic Chemistry. v.37, n.22, p.3404-3409, 1972.

CHAN, W.C.; WHITE, P.D. Fmoc solid phase peptide synthesis. Oxford University Press; New York, 2000.

CHEN, R. Bacterial expression systems for recombinant protein production: E. coli and beyond. Biotechnology Advances. v.30, n.5, p.1102-1107, 2012.

CHOU, C.P. Engineering cell physiology to enhance recombinant protein production in Escherichia coli. Applied Microbiology and Biotechnology. v.76, n.3, p.521-532, 2007. 
DALE, C.S.; PAGANO, R.L.; RIOLI, V. Hemopressin: a novel bioactive peptide derived from the $\alpha 1$-chain of hemoglobin. Mem Inst Oswaldo Cruz. v.100, n.1, p.105$106,2005$.

DAVIS, T.P.; GILLESPIE, T.J.; PORRECA, F. Peptide fragments derived from the beta-chain of hemoglobin (hemorphins) are centrally active in vivo. Peptides. v.10, n.4, p.747-751, 1989.

D'HONDT, M.; BRACKE, N.; TAEVERNIER, L.; GEVAERT, B.; VERBEKE, F.; WYNENDAELE, E.; DE SPIEGELEER, B. Related impurities in peptide medicines. Journal of Pharmaceutical and Biomedical Analysis. v.101, p.2-30, 2014.

DI MARZO, V. Targeting the endocannabinoid system: to enhance or reduce? Nature Reviews Drug Discovery. v.7, n.5, p.438-455, 2008.

DI MARZO, V.; PETROSINO, S. Endocannabinoids and the regulation of their levels in health and disease. Current Opinion in Lipidology. v.18, n.2, p.129-140, 2007.

DODD, G.T.; MANCINI, G.; LUTZ, B.; LUCKMAN, S.M. The Peptide Hemopressin Acts through CB1 Cannabinoid Receptors to Reduce Food Intake in Rats and Mice. The Journal of Neuroscience. v.30, n.21, p.7369-7376, 2010.

DVORACSKO, S.; TOMBOLY, C.; BERKECZ, R.; KERESZTES, A. Investigation of receptor binding and functional characteristics of hemopressin(1-7). Neuropeptides. v.58, p.15-22, 2016.

EL-FAHAM, A.; ALBERICIO, F. Peptide Coupling Reagents, More than a Letter Soup. Chemical Reviews. v.111, n.11, p. 6557-6602, 2011.

EL SWEFY, S.; HASAN, R.A.; IBRAHIM, A.; MAHMOUD, M.F. Curcumin and hemopressin treatment attenuates cholestasis-induced liver fibrosis in rats: role of CB1 receptors. Naunyn-Schmiedeberg's Archives of Pharmacology. v.389, n.1, p.103-116, 2016.

FERRO, E.S. Biotecnologia translacional: hemopressina e outros peptídeos intracelulares. Estudos avançados. v.24, n.70, 2010.

FOGAÇA, M.V.; SONEGO, A.B.; RIOLI, V.; GOZZO, F.C.; DALE, C.S.; FERRO, E.S.; GUIMARÃES, F.S. Anxiogenic-like effects induced by hemopressin in rats. Pharmacology, Biochemistry and Behavior. v.129, p.7-13, 2015.

FOSGERAU, K.; HOFFMANN, T. Peptide therapeutics: current status and future directions. Drug Discovery Today. v.20, n.1, p.122-128, 2015.

FRANCISCHETTI, E.A.; ABREU, V.G. O Sistema Endocanabinóide: Nova Perspectiva no Controle de Fatores de Risco Cardiometabólico. Arquivos Brasileiros de Cardiologia. v.87, n.4, p.548-558, 2006. 
FUKUI, K.; SHIOMI, H.; TAKAGI, H.; HAYASHI, K.; KISO, Y.; KITAGAWA, K. Isolation from bovine brain of a novel analgesic pentapeptide, neo-kyotorphin, containing the Tyr-Arg (kyotorphin) unit. Neuropharmacology. v.22, n.2, p.191-196, 1983.

GAO, M.; MA, C.; LIU, W.; ZHU, J.; TIAN, H.; GAO, X.; YAO, W. Production and purification of an analog of glucagon-like peptide-1 by auto-induction and on-column cleavage in Escherichia coli. World Journal of Microbiology and Biotechnology, v.26, n.9, p.1675-1682. 2010.

GELMAN, J.S.; FRICKER, L.D. Hemopressin and other bioactive peptides from cytosolic proteins: Are these non-classical neuropeptides? The AAPS Journal. v.12, n.3, p.279-289, 2010.

GELMAM, J.S.; SIRONI, J.; CASTRO, L.M.; FERRO, E.S.; FRICKER, L.D. Hemopressins and other hemoglobin-derived peptides in mouse brain: comparison between brain, blood, and heart peptidome and regulation in $\mathrm{Cpe}^{\mathrm{fat} / \mathrm{fat}}$ mice. Journal of Neurochemistry. v.113, n.4, p.871-880, 2010.

GODOY-MATOS, A.F.; GUEDES, E.P.; SOUZA, L.L.; VALÉRIO, C.M. O Sistema Endocanabinóide: Novo Paradigma no Tratamento da Síndrome Metabólica. Arquivos Brasileiros de Endocrinologia \& Metabologia. v.50, n.2, p.390-399, 2006.

GOMES, I.; DALE, C.S.; CASTEN, K.; GEIGNER, M.A.; GOZZO, F.C.; FERRO, E.S.; HEIMANN, A.S.; DEVI, L.A. Hemoglobin-derived peptides as novel type of bioactive signaling molecules. The AAPS Journal. v.12, n.4, p.658-669, 2010.

GOMES, I.; GRUSHKO, J.S.; GOLEBIEWSKA, U.; HOOGENDOORN, S.; GUPTA, A.; HEIMANN, A.S.; FERRO, E.S.; SCARLATA, S.; FRICKER, L.D.; DEVI, L.A. Novel endogenous peptide agonists of cannabinoid receptors. The FASEB Journal. v.23, n.9, p.3020-3029, 2009.

HANDBOOK. Protein Purification. GE Healthcare. 96f. 2001.

HEIMANN, A.S.; GOMES, I.; DALE, C.S.; PAGANO, R.L.; GUPTA, A.; SOUZA, L.L.; LUCHESSI, A.D.; CASTRO, L.M.; GIORGI, R.;RIOLI, V.; FERRO, E.S.; DEVI, L.A. Hemopressin is an inverse agonist of CB1cannabinoid receptors. PNAS. v.104, n.51, p.20588-20593, 2007.

HUANG, C.J; LIN, H.; YANG, X. Industrial production of recombinant therapeutics in Escherichia coli and its recent advancements. Journal of Industrial Microbiology \& Biotechnology. v.39, n.3, p.383-399, 2012.

ÍNTEGRA BRASIL. Agência de Integração à Saúde, Meio Ambiente e Desenvolvimento Social do Brasil. III Fórum Nacional Sobre Inovação e Tecnológica na Área de Saúde no Brasil. 2011.

INTERFARMA - Associação da Indústria Farmacêutica de Pesquisa. Entendendo os medicamentos biológicos. 28f. São Paulo, BR-SP. 2012. 
ISIDRO-LlOBET, A.; ÁlVAREZ, M.; ALBERICIO, F. Amino Acid-Protecting Groups. Chemical Reviews. v.109, n.6, p. 2455-2504, 2009.

IVERSEN, L.; CHAPMAN, V. Cannabinoids: a real prospect for pain relief? Current Opinion in Pharmacology. v.2, n.1, p.50-55, 2002.

JAGEROVIC, N.; FERNANDEZ-FERNANDEZ, C.; GOYA, P. CB1 Cannabinoid antagonists: Structure-activity relationships and potential therapeutic applications. Current Topics in Medicinal Chemistry. v.8, n.3, p.205-230, 2008.

JULIANO, L. Química de peptídeos: Uma breve revisão dos processos de síntese. Química Nova, v.13, n.3, p.176-190, 1990.

KISO, Y.; KITAGAWA, K.; KAWAI, N.; AKITA, T.; TAKAGI, H.; AMANO, H.; FUKUI, K. Neo-kyotorphin (Thr-Ser-Lys-Tyr-Arg), a new analgesic peptide. Febs Letters. v.155, n.2, p. 281-284, 1983.

LANTZ, I.; GLAMSTA, E.L.; TALBACK, L.; NYBERG, F. Hemorphins derived from hemoglobin have an inhibitory action on angiotensin converting enzyme activity. Febs Letters. v.287, n.1-2, p.39-41, 1991.

LEBENDIKER, M.; DANIELI, T. Production of prone-to-aggregate proteins. FEBS Letters. v.588, n.2, p.236-246, 2014.

LEONE, S.; RECINELLA, L.; CHIAVAROLI, A.; MARTINOTTI, S.; FERRANTE, C.; MOLLICA, A.; MACEDONIO, G.; STEFANUCCI, A.; DVORACSKO, S.; TOMBOLY, C.; DE PETROCELLIS, L.; VACCA, M.; BRUNETTI, L.; ORLANDO, G. Emotional disorders induced by Hemopressin and RVD-hemopressin $(\alpha)$ administration in rats. Pharmacological Reports. v.69, n.6, p.1247-1253, 2017.

LI, X.; ZHANG, G.; AN, G.; LIU, S.; LAI, Y. Expression, purification and anticancer analysis of GST-tagged human perforin and granzyme B proteins in human laryngeal cancer Hep-2 cells. Protein Expression and Purification. v. 95, p. 38-43. 2014.

LIPPTON, H.; LIN, B.; GUMUSEL, B.; WITRIOL, N.; WASSERMAN, A.; KNIGHT, M. Hemopressin, a hemoglobin fragment, dilates the rat systemic vascular bed through release of nitric oxide. Peptides. v. 2 7, p. 2284-2288. 2006.

LIU, Y.; REN, L.; GE, L.; CUI, Q.; CAO, X.; HOU, Y.; BAI, F.; BAI, G. A strategy for fusion expression and preparation of functional glucagon-like peptide-1 (GLP-1) analogue by introducing an enterokinase cleavage site. Biotechnology Letters. 2014.

MACHADO, A.; LIRIA, C.W.; PROTI, P.B.; REMUZGO, C.; MIRANDA, M.T.M.

Sínteses química e enzimática de peptídeos: princípios básicos e aplicações. Química Nova, v.27, n.5, p.781-789, 2004.

MACKIE, K. Cannabinoid receptors as therapeutic targets. Annual Review of Pharmacology and Toxicology. v.46, p.101-122, 2006. 
MALIK, A. Protein fusion tags for efficient expression and purification of recombinant proteins in the periplasmic space of E. coli. 3 Biotech. v.6, n.1, p.44, 2016.

MERRIFIELD, R.B. Solid phase peptide synthesis. I. The synthesis of a tetrapeptide. Journal of the American Chemical Society. v.85, n.14, p.2149-2154, 1963.

NGUYEN, M.T.; KOO, B.K.; THI, V.T.T.; SONG, J.A.; CHONG, S.H.; JEONG, B.; RYU, H.B.; MOH, S.H.; CHOE, H. Prokaryotic soluble overexpression and purification of bioactive human growth hormone by fusion to thioredoxin, maltose binding protein, and protein disulfide isomerase. PLos One. v.9, n.3, p.1-10, 2014.

NYBERG, F.; SANDERSON, K.; GLAMSTA, E.L. The hemorphins: A new class of opioid peptides derived from the blood protein hemoglobin. Biopolymers. v.43, n.2, p.147-156, 1997.

PACHER, P.; BATKAI, S.; KUNOS, G.; The endocannabinoid system as an emerging target of pharmacotherapy. Pharmacological Reviews. v.58, n.3, p.389-462, 2006.

PAPANEOPHYTOU, C.P.; KONTOPIDIS, G. Statistical approaches to maximize recombinant protein expression in Escherichia coli: A general review. Protein Expression and Purification. v.94, p.22-32, 2014.

PIMENTA, C.G. O ambiente institucional da biotecnologia voltada para a saúde humana no Brasil. 2008. 133f. Dissertação. (Mestre em Desenvolvimento Sustentável) Universidade de Brasília - UnB.

REDDY, P.A.; JONES, S.T.; LEWIN, A.H.; CARROLL, F.I. Synthesis of hemopressin peptides by classical solution phase fragment condensation. International Journal of peptides. v.2012. p.1-5, 2012.

RICHTER, F.; MEURERS, B.H.; ZHU, C.; MEDVEDEVA, V.P.; CHESSELET, M-F. Neurons express hemoglobin $\alpha$ - and $\beta$-chains in rat and human brains. The Journal of comparative neurology. v.5, n.515, p.538-547, 2009.

RINAS, U.; GARCIA-FRUITOS, E.; CORCHERO, J.L.; VAZQUEZ, E.; SERASFRANZOSO, J.; VILLAVERDE, A. Bacterial Inclusion Bodies: Discovering Their Better Half. Trends in Biochemical Sciences. v.42, n.9, p.726-737, 2017.

RIOLI, V.; GOZZO, F. C.; HEIMANN, A. S; LINARDI, A.; KRIEGER, J. E.; SHIDA, C.; ALMEIDA, P. C.; HYSLOP, S.; EBERLIN, M. N.; FERRO, E. S. Novel Natural Peptide Substrates for Endopeptidase 24.15, Neurolysin, and Angiotensin-converting Enzyme. The Journal of Biological Chemistry. v.278, n.10, p. 8547-8555, 2003.

RODRÍGUEZ, V.; ASENJO, J.A.; ANDREWS, B.A. Design and implementation of a high yield production system for recombinant expression of peptides. Microbial Cell Factories. v.13, n.1, p.65, 2014.

ROSANO, G.L.; CECCARELLI, E.A. Recombinant protein expression in Escherichia coli: advances and challenges. Frontiers in Microbiology. v.5, n.172, 2014. 
SAMBROOK, J. \& RUSSELL, D.W. The condensed protocols. From molecular cloning. A laboratory manual. 1 ed. Editora CSHL. 2006.

SZLAVICZ, E.; PERERA, P.S.; TOMBOLY, C.; HELYES, Z.; ZADOR, F.; BENYHE, S.; BORSODI, A.; BOJNIK, E. Further Characterization of Hemopressin Peptide Fragments in the Opioid and Cannabinoid Systems. Anesthesia \& Analgesia. v.121, n.6, p.1488-1494, 2015.

TANAKA, K.; SHIMIZU, T.; YANAGITA, T.; NEMOTO, T.; NAKAMURA, K.; TANIUCHI, K.; DIMITRIADIS, F.; YOKOTANI, K.; SAITO, M. Brain RVDhemopressin, a haemoglobin-derived peptide, inhibits bombesin-induced central activation of adrenomedullary outflow in the rat. British Journal of Pharmacology. v.171, n.1, p.202-213, 2014.

TROLL, W.; CANNAN, R. K. A modified photometric ninhydrin method for the analysis of amino and imino acids. Journal of Biological Chemistry, v.200, n.2, p.803811. 1953.

VAN DORPE, S.; VERBEKEN, M.; WYNENDAELE, E.; DE SPIEGELEER, B. Purity profiling of peptide drugs. Journal of Bioanalysis \& Biomedicine. 2011.

VERBEKE, F.; WYNENDAELE, E.; BRAET, S.; D'HONDT, M.; DE SPIEGELEER, B. Quality evaluation of synthetic quorum sensing peptides used in R\&D. Journal of Pharmaceutical Analysis. v.5, n.3, p.169-181, 2015.

VLIEGHE, P.; LISOWSKI, V.; MARTINEZ, J.; KHRESTCHATISKY, M. Synthetic therapeutic peptides: science and market. Drug Discovery Today, v.15, p.40-56, 2010.

WALLS, D.; LOUGHRAN, S.T. Tagging recombinant proteins to enhance solubility and aid purification. Protein Chromatography: Methods and Protocols, Methods in Molecular Biology. v.681, n.1, p.151-175, 2011.

WANG, W. Instability, stabilization, and formulation of liquid protein pharmaceuticals. International Journal of Pharmaceutics, v.185, n.2, p.129-188, 1999.

XAPELLI, S.; AGASSE, F.; GRADE, S.; BERNARDINO, L.; RIBEIRO, F.; SCHITINE, C.; HEIMANN, A.; FERRO, E.; SEBASTIÃO, A.M.; REIS, R.A.M.; Modulation of subventricular zone oligodendrogenesis: a role for hemopressin? Frontiers in Cellular Neuroscience. v.8, n.59, p. 1-9, 2014.

YU, H.; MA, Q.; LIN, J.; SUN, Y.F.; ZHENG, F. Expression and purification of GSTFHL2 fusion protein. Genetics and Molecular Research Journal. v.12, n.4, p.63726378, 2013.

ZHANG, R.S.; HE, Z.; JIN, H.D.; WANG, R. Effects of the cannabinoid 1 receptor peptide ligands hemopressin, (m)RVDhemopressin( $\alpha$ ) and $(\mathrm{m}) \mathrm{VD}$-hemopressin $(\alpha)$ on memory in novel object and object location recognition tasks in normal young and $A \beta_{1-}$ 42-treated mice. Neurobiology of Learning and Memory. v.134, p.264-274, 2016. 
ZHAO, Q.; GARREAU, I.; SANNIER, F.; PIOT, J.M. Opioid peptides derived from hemoglobin: Hemorphins. Biopolymers. v.43, n.2, p.75-98, 1997.

ZHENG, T.; ZHANG, T.; ZHANG, R.; WANG, Z.L; HAN, Z.L.; HAN, Z.L.; LI, N.; LI, X.H.; ZHANG, M.N.; XU, B. Pharmacological characterization of rat VDhemopressin $(\alpha)$, an $\alpha$-hemoglobin-derived peptide exhibiting cannabinoid agonist-like effects in mice. Neuropeptides. v.63, p.83-90, 2017.

ZHOU, L.; JIN, Q.; YANG, Y.; LIU, Z.; LI, X.; DONG, S.; ZHAO, L. Effects of endokinin $\mathrm{A} / \mathrm{B}$ and endokinin $\mathrm{C} / \mathrm{D}$ on the antinociception properties of hemopressin in mice. Peptides. v. 38, p. 70-80, 2012.

ZOU, Z.; CAO, L.; ZHOU, P.; SU, Y.; SUN, Y.; LI, W. Hyper-acidic protein fusion partners improve solubility and assist correct folding of recombinant proteins expressed in Escherichia coli. Journal of Biotechnology. v.135, n.4, p.333-339, 2008. 